\title{
Cannabinoids Desensitize Capsaicin and Mustard Oil Responses in Sensory Neurons via TRPA1 Activation
}

\author{
Armen N. Akopian, ${ }^{1}$ Nikita B. Ruparel, ${ }^{1}$ Amol Patwardhan, ${ }^{1}$ and Kenneth M. Hargreaves ${ }^{1,2}$ \\ Departments of ${ }^{1}$ Endodontics and ${ }^{2}$ Pharmacology, University of Texas Health Science Center at San Antonio, San Antonio, Texas 78229
}

\begin{abstract}
Although the cannabinoid agonists $R$-(+)-(2,3-dihydro-5-methyl-3-[(4-morpholinyl)methyl]pyrol[1,2,3-de]-1,4-benzoxazin-6-yl)-(1naphthalenyl) methanone mesylate [WIN 55,212-2 (WIN)] and (R,S)-3-(2-iodo-5-nitrobenzoyl)-1-(1-methyl-2-piperidinylmethyl)-1 $H$ indole (AM1241) exert peripheral antihyperalgesia in inflammatory pain models, the mechanism for cannabinoid-induced inhibition of nociceptive sensory neurons has not been fully studied. Because TRPV1 and TRPA1 channels play important roles in controlling hyperalgesia in inflammatory pain models, we investigated their modulation by WIN and AM1241. The applications of WIN $(>5 \mu \mathrm{M})$ and AM1241 $(>30 \mu \mathrm{M})$ inhibit responses of sensory neurons to capsaicin and mustard oil. To determine potential mechanisms for the inhibition, we evaluated cannabinoid effects on nociceptors. WIN and AM1241 excite sensory neurons in a concentration-dependent manner via a nonselective $\mathrm{Ca}^{2+}$-permeable channel. The expression of TRP channels in CHO cells demonstrates that both WIN and AM1241 activate TRPA1 and, by doing so, attenuate capsaicin and mustard oil responses. Using TRPA1-specific small interfering RNA or TRPA1-deficient mice, we show that the TRPA1 channel is a sole target through which WIN and mustard oil activate sensory neurons. In contrast, AM1241 activation of sensory neurons is mediated by TRPA1 and an unknown channel. The knockdown of TRPA1 activity in neurons completely eliminates the desensitizing effects of WIN and AM1241 on capsaicin-activated currents. Furthermore, the WIN- or AM1241-induced inhibition of capsaicin-evoked nocifensive behavior via peripheral actions is reversed in TRPA1 null-mutant mice. Together, this study demonstrates that certain cannabinoids exert their peripheral antinocifensive actions via activation of the TRPA1 channel on sensory neurons.
\end{abstract}

Key words: cannabinoid; TRPA1; TRPV1; nociceptor; pain; trigeminal

\section{Introduction}

Cannabinoids produce profound supraspinal, spinal, and peripheral antinociception and antihyperalgesia in several acute and chronic pain states (Calignano et al., 1998; Richardson et al., 1998; Rice et al., 2002; Croxford, 2003). Thus, $R$-(+)-(2,3-dihydro-5-methyl-3-[(4-morpholinyl)methyl]pyrol[1,2,3-de]-1,4-benzoxazin-6-yl)-(1-naphthalenyl) methanone mesylate [WIN 55,212-2 (WIN)] and (R,S)-3-(2-iodo-5-nitrobenzoyl)-1-(1methyl-2-piperidinylmethyl)- $1 H$-indole (AM1241), belonging to the aminoalkylindole family of cannabinoids, produce peripherally mediated antinociception in acute pain models (Malan et al., 2001; Dogrul et al., 2003) and alleviate hyperalgesia/allodynia induced by capsaicin (CAP) (Johanek et al., 2001; Hohmann et

\footnotetext{
Received April 11, 2006; revised Nov. 30, 2007; accepted Dec. 4, 2007.

This work was supported by National Institutes of Health (NIH)-National Institute of Dental and Craniofacial Research Grant DE014928 (A.N.A.) and NIH-National Institute on Drug Abuse Grant DA19585 (K.M.H.). We acknowledge Dr. Xiaoling Sun and Gabriela Helesic for technical assistance with the experiments. We thank Dr. Kevin Kwan and Dr. David Corey (Harvard University, Boston, MA) for providing TRPA1 null-mutant mice; Dr. Andrea Giuffrida (University of Texas Health Science (enter at San Antonio, San Antonio, TX) for kindly gifting CB $B_{1}$ null-mutant mice; Dr. David Julius (University of California at San Francisco, San Francisco, CA) for kindly gifting rTRPV1 CDNA; Dr. Ardem Patapoutian (The Scripps Research Institute, San Diego, CA) for providing TRPA1, TRPV2-TRPV4, and TRPM8 CDNAs; and Dr. Alexandros Makriyannis (University of Connecticut, Storrs, $(T)$ for providing the cannabinoid AM1241.

Correspondence should be addressed to Armen N. Akopian, University of Texas Health Science Center at San Antonio, 7703 Floyd Curl Drive, San Antonio, TX 78229-3900. E-mail: akopian@uthscsa.edu.

DOI:10.1523/JNEUROSCI.1565-06.2008

Copyright $\odot 2008$ Society for Neuroscience $\quad$ 0270-6474/08/281064-12\$15.00/0
}

al., 2004), heat (Johanek and Simone, 2004), inflammation (Nackley et al., 2003; Quartilho et al., 2003), and nerve injury (Fox et al., 2001; Ibrahim et al., 2003).

Several mechanisms for the peripheral inhibitory effects of cannabinoids have been suggested. A direct inhibition of nociceptive sensory neurons (i.e., nociceptors) could be mediated via the $\mathrm{G}_{\mathrm{i} / \mathrm{o}}$-protein-coupled cannabinoid receptors, $\mathrm{CB}_{1}$ (Matsuda et al., 1990) or/and $\mathrm{CB}_{2}$ (Munro et al., 1993). However, a number of studies have demonstrated that $\mathrm{CB}_{1}$ has little-to-no coexpression with nociceptive markers such as the TRPV1 and calcitonin gene related peptide (CGRP) in native rat dorsal root ganglia (DRGs) (Hohmann and Herkenham, 1999; Bridges et al., 2003) and trigeminal ganglia (TGs) (Price et al., 2003). Appreciable levels of $\mathrm{CB}_{2}$ have also not been detected in sensory ganglia (Price et al., 2003). Other reports indicate that $\mathrm{CB}_{1}$ and $\mathrm{CB}_{2}$ expression could be observed in cultured (Ahluwalia et al., 2000; Ross et al., 2001) as well as native DRG neurons (Amaya et al., 2006; Binzen et al., 2006; Agarwal et al., 2007). Nevertheless, (-)-cis-3-[2-hydroxy4-(1,1-dimethylheptyl) phenyl] trans-4-(3-hydroxypropyl)cyclohexanol $(\mathrm{CP} 55,940)$, a dual $\mathrm{CB}_{1} / \mathrm{CB}_{2}$ agonist, inhibits the depolarization-evoked increase in intracellular $\mathrm{Ca}^{2+}\left(\left[\mathrm{Ca}^{2+}\right]_{\mathrm{i}}\right)$ primarily in non-nociceptive (i.e., large diameter) neurons (Khasabova et al., 2002, 2004). Moreover, depolarization-evoked CGRP release from TG neurons has also not been attenuated by concentrations of WIN capable of activating $\mathrm{CB}_{1} / \mathrm{CB}_{2}$ (Price et al., 2004b).

Alternatively, an indirect inhibition of nociceptors could oc- 
cur through cannabinoid-induced modulation of peripheral non-neuronal cell activities, which play a pivotal role in inflammatory hyperalgesia and neuropathic pain (Woolf et al., 1996; Perkins and Tracey, 2000). Thus, cannabinoids acting via $\mathrm{CB}_{2} \mathrm{can}$ prevent mast cell degranulation and neutrophil accumulation (Jaggar et al., 1998; Calignano et al., 2001). Activation of $\mathrm{CB}_{2}$ on keratinocytes can also stimulate release of $\beta$-endorphin that produces thermal antinociception (Ibrahim et al., 2005). Activation of the $\mathrm{CB}_{1}$ receptor mediates the inhibition of keratinocytes (Maccarrone et al., 2003) and suppresses secretory responses of mast cells (Samson et al., 2003).

Accumulated data also support the possibility of $\mathrm{CB}_{1} / \mathrm{CB}_{2}-$ independent peripheral cannabinoid effects (Ralevic and Kendall, 2001; Duncan et al., 2004; Sagar et al., 2004). The potential role of TRPV1 in these actions has been hypothesized (Price et al., 2004a; Sagar et al., 2004). Indeed, certain cannabinoids [i.e., anandamide (AEA), $N$-(2-chloroethyl)-5Z,8Z,11Z,14Z-eicosatetraenamide (ACEA), $N$-arachidonoyl-dopamine (NADA), and $\delta(9)$ tetrahydrocannabinol] can elevate $\left[\mathrm{Ca}^{2+}\right]_{\mathrm{i}}$ in nociceptors by gating TRPV1 or TRPA1 channels (Zygmunt et al., 1999; Huang et al., 2002; Jordt et al., 2004; Price et al., 2004a). An elevation of $\left[\mathrm{Ca}^{2+}\right]_{\mathrm{i}}$ can ignite numerous cellular cascades, including induction of $\mathrm{Ca}^{2+}{ }_{-}$ dependent kinases and phosphatases. It is well established that these enzymes can be effective modulators of TRPV1 activities by functional desensitization (Docherty et al., 1996; Koplas et al., 1997; Distler et al., 2003; Jung et al., 2004). Thus, one hypothesis is that certain cannabinoids could inhibit nociceptors by activating $\mathrm{Ca}^{2+}$ permeable channels. In the present study, we tested the hypothesis that WIN- and AM1241-induced direct inhibition of nociceptors is mediated by activation of TRPA1.

\section{Materials and Methods}

Animals and primary sensory neuron culture. Breeding colonies for TRPA1 channel, $\mathrm{CB}_{1}$ and $\mathrm{CB}_{2}$ receptor null-mutant mice were provided by Dr. Kevin Kwan (Harvard University, Boston, MA), Dr. Andrea Giuffrida (University of Texas Health Science Center at San Antonio, San Antonio, TX), and The Jackson Laboratory (Bar Harbor, ME), respectively. TRPA1 null-mutant mice were generated on the B6129P1/F2J background. $\mathrm{CB}_{1}$ and $\mathrm{CB}_{2}$ null-mutant mice were generated on the C57BL/6J background.

TG neuronal cultures from adult Sprague Dawley rats, wild-type, or TRPA1 null-mutant B6129P1/F2J mice were established as described previously (Patwardhan et al., 2006b). Sensory neurons were plated at low density on poly-D-lysine/laminin-coated coverslips (Clontech, Palo Alto, CA). Cells were maintained in the presence of $100 \mathrm{ng} / \mathrm{ml} \mathrm{NGF-}$ 7.02S (Harlan, Indianapolis, IN). The culturing times (1-4 d) for the particular experiments are indicated in the figure legends.

Constructs and heterologous expression in Chinese hamster ovary cells. Expression plasmids of rat TRPV1 (accession no. NM031982) in pcDNA3 (Invitrogen, Carlsbad, CA); mouse TRPA1 (NM177781), mouse TRPV3 (NM145099), rat TRPV4 (NM023970), and mouse TRPM8 (NM134252) all in pcDNA5/FRT (Invitrogen); and rat TRPV2 (NM017207) in pcDNA3.1(+) (Invitrogen) were used. Expression constructs with a visual marker (green fluorescent protein expressing pEGFP-N1 from Clontech) were delivered into Chinese hamster ovary (CHO) cells using PolyFect (Qiagen, Valencia, CA) according to manufacturers' protocols. $\mathrm{CHO}$ cells were subjected to experimental procedures within $36-72 \mathrm{~h}$ after transfection.

Electrophysiology. If not otherwise specified, recordings were made in perforated-patch voltage clamp [holding potential $\left(V_{\mathrm{h}}\right)$ of $-60 \mathrm{mV}$ ] configuration at $22-24^{\circ} \mathrm{C}$ from the somata of neurons $(15-40 \mathrm{pF})$ or CHO cells. Data were acquired and analyzed using an Axopatch 200B amplifier and pCLAMP9.0 software (Molecular Devices, Union City, CA). Recording data were filtered at $0.5-2.5 \mathrm{kHz}$ and sampled at $2-10$ $\mathrm{kHz}$ depending on current kinetics. Borosilicate pipettes (Sutter, Novato, CA) were polished to resistances of 4-7 M $\Omega$ in the perforated-patch pipette solution. Access resistance $\left(R_{\mathrm{s}}\right)$ was compensated $(40-80 \%)$ when appropriate up to the value of 13-18 M $\Omega$. Data were rejected when $R_{\mathrm{s}}$ changed $>20 \%$ during recording, leak currents were $>50 \mathrm{pA}$, or input resistance was $<300 \mathrm{M} \Omega$. Currents were considered positive when their amplitudes were fivefold larger than displayed noise (in root mean square).

Cell diameters were calculated using $d=\sqrt{ }\left[100 \times C_{\mathrm{m}} / \pi\right]$, where $d$ (in micrometers) is cell diameter and $C_{\mathrm{m}}$ (in picofarads) is membrane capacitance. Concentration-response curves were fitted to the Hill equation $I / I_{\max }=1 /\left[1+\left(\mathrm{EC}_{50} / C\right)^{h}\right]$, where $\mathrm{EC}_{50}$ is the half-maximal effective concentration, $C$ is the drug concentration, $h$ is the Hill coefficient, and $I_{\max }$ is the maximum current. The fitting with the Hill equation was also used to calculate the half-maximal inhibitory concentrations $\left(\mathrm{IC}_{50}\right)$ of the cannabinoids. $I-V$ relationships were established at peak currents applying voltage-ramp protocols as described previously (Liu et al., 1997).

Standard external solution (SES) contained the following (in mM): 140 $\mathrm{NaCl}, 5 \mathrm{KCl}, 2 \mathrm{CaCl}_{2}, 1 \mathrm{MgCl}_{2}, 10$ D-glucose, and $10 \mathrm{HEPES}, \mathrm{pH}$ 7.4. To determine $\mathrm{I}-\mathrm{V}$ relationships, $\mathrm{Mg}^{2+}$-free solutions containing the following (in mM): 10 HEPES, 10 D-glucose, 0.0003 TTX (Tocris, Ellisville, $\mathrm{MO}$ ), and 0.1 verapamil (Tocris), in addition to the stated concentration of $\mathrm{Na}^{+}$and $\mathrm{Ca}^{2+}$, were used. NMDG ( $\mathrm{N}$-methyl-D-glucamine) was used as a $\mathrm{Na}^{+}$substitute. The pipette solution for the perforated-patch configurations consisted of the following (in $\mathrm{mm}$ ): $110 \mathrm{~K}$-methanesulfonate, $30 \mathrm{KCl}, 1 \mathrm{MgCl}_{2}, 10$ HEPES, pH 7.3, and $250 \mu \mathrm{g} / \mathrm{ml}$ amphotericin B (Sigma, St. Louis, MO). The standard pipette solution (SIS) for the whole-cell configurations contained the following (in mM): $140 \mathrm{KCl}, 1$ $\mathrm{MgCl}_{2}, 1 \mathrm{CaCl}_{2}, 10$ EGTA, 10 D-glucose, 10 HEPES, $0.2 \mathrm{Na}$-GTP, and 2.5 Mg-ATP, $\mathrm{pH}$ 7.3. In a set of experiments designed to suppress voltageactivated $\mathrm{K}^{+}$currents, $\mathrm{KCl}$ was equimolarly substituted with $\mathrm{CsCl}$. Drugs were applied using a fast, pressure-driven, and computercontrolled eight-channel system (AutoMate Scientific, San Francisco, CA).

$\mathrm{Ca}^{2+}$ imaging in TG neurons and $\mathrm{CHO}$ cells. The $\mathrm{Ca}^{2+}$ imaging experiments were performed in standard solution (i.e., SES) as described previously (Jeske et al., 2006; Patwardhan et al., 2006b). The net changes in $\mathrm{Ca}^{2+}$ influx were calculated by subtracting the basal $\left[\mathrm{Ca}^{2+}\right]_{\mathrm{i}}$ (mean value collected for $60 \mathrm{~s}$ before agonist addition) from the peak $\left[\mathrm{Ca}^{2+}\right]_{\mathrm{i}}$ value achieved after exposure to the agonists. $\mathrm{Ca}^{2+}$ increases above $50 \mathrm{~nm}$ were considered positive. This minimal threshold criterion was established by application of $0.1 \%$ DMSO as a vehicle. Ratiometric data were converted to $\left[\mathrm{Ca}^{2+}\right]_{\mathrm{i}}$ (in micromolar concentration) by using the equation $\left[\mathrm{Ca}^{2+}\right]_{\mathrm{i}}$ $=K^{\star}\left(R-R_{\min }\right) /\left(R_{\max }-R\right)$, where $R$ is the $340 / 380 \mathrm{~nm}$ fluorescence ratio. $R_{\min }, R_{\max }$, and $K^{\star}$ were measured according to a previously described method (Gamper and Shapiro, 2003).

Ablation of TRPA1 activity in TG neurons with TRPA1-specific small interference RNA. Double-stranded, HPLC-purified small interference RNA (siRNA) directed against rat TRPA1 (ALab-1, GGAACUGCAUACCAACUU-dTdT) was custom labeled with Alexa Fluor 488 and synthesized by Qiagen (Valencia, CA). Unlabeled siRNA against rat TRPA1 (AA-1, CGATAGCAATATTCTTCTA-dTdT; AB-1, GGATGAACTTCCTACTATA-dTdT) and Drosophila TRPA1 (ADr-1, GCAAUGUCATCGAUAUUCA-dTdT) were synthesized by Dharmacon RNA Technologies (Chicago, IL). Silencer Negative Control no. 1 siRNA was used as the scrambled negative control (Ambion, Austin, TX). The experimental details for siRNA transfection into sensory neurons were previously described (Jeske et al., 2006). The transfection procedure was conducted once (on day 1) for $\mathrm{Ca}^{2+}$ imaging and electrophysiology. Cells were analyzed (i.e., $\mathrm{Ca}^{2+}$ imaging or recording) on days 2-3.

Behavioral assay. On the day of the experiment, CAP (Fluka, St. Louis, MO) was dissolved in 20\% methylpyrrolidinone (MPN) solution, WIN (Tocris; stock prepared in DMSO) was diluted in 20\% MPN solution, and AM1241 (stock prepared in 100\% MPN) was diluted in 50\% MPN solution. All mice were acclimatized for at least $30 \mathrm{~min}$ before testing. Appropriate vehicle controls were used for individual experiments. All observers were blinded to treatment allotment.

For experiments evaluating the effect of WIN on CAP-induced behavior, the plantar surface of the right hindpaw of the animals was coinjected with either vehicle plus CAP $(0.5 \mu \mathrm{g})$ or WIN $(2.5 \mu \mathrm{g})$ plus CAP $(0.5 \mu \mathrm{g})$ 
in $20 \mu \mathrm{l}$ injection volume. For experiments evaluating the effect of AM1241 on CAP-induced nocifensive behavior, the plantar surface of the right hindpaw of the animal was injected with vehicle or AM1241 (40 $\mu \mathrm{g})$ in $15 \mu \mathrm{l}$ injection volume. The animals were then injected with CAP $(0.5 \mu \mathrm{g})$ in $10 \mu \mathrm{l}$ injection volume. The time spent by the animal demonstrating grooming and flinching of the injected hindpaw over a $5 \mathrm{~min}$ period was collected as a measure of nocifensive behavior (Caterina et al., 2000; Bautista et al., 2006; Kwan et al., 2006).

For experiments evaluating the peripheral action of cannabinoids, the contralateral hindpaw of mice was injected with $20 \mu \mathrm{l}$ of either vehicle or a cannabinoid, whereas the ipsilateral paw was injected with $20 \mu \mathrm{l}$ of vehicle, and then (after $15 \mathrm{~min})$ with CAP $(0.5 \mu \mathrm{g})$. For experiments evaluating the peripheral action of AM1241, the contralateral hindpaw of mice was injected with $15 \mu \mathrm{l}$ of either vehicle or AM1241 $(40 \mu \mathrm{g})$, whereas the ipsilateral paw was injected with $15 \mu \mathrm{l}$ of vehicle, and then (after $15 \mathrm{~min}$ ) the ipsilateral paw was injected with $10 \mu \mathrm{l}$ of CAP $(0.5 \mu \mathrm{g})$.

Data analysis. For statistical analysis, GraphPad Prism 4.0 (GraphPad, San Diego, CA) was used. The data in the figures are given as mean \pm SEM, with the value of $n$ referring to the number of analyzed cells or trials for each group. All experiments were performed at least in triplicate. The significant difference between groups was assessed by one-way ANOVA with Dunnett's multiple-comparison post hoc test. Two conditions were compared using paired or unpaired $t$ test. A difference was accepted as significant when $p<0.05,<0.01$, or $<0.001$ and are identified by ${ }^{*}$, ${ }^{* *}$, and ${ }^{* * *}$, respectively.

\section{Results}

WIN and AM1241 inhibit capsaicin and mustard oil responses in TG neurons

$\mathrm{A} \mathrm{CB}_{1} / \mathrm{CB}_{2}$ dual agonist WIN and a $\mathrm{CB}_{2}$ agonist AM1241 (Ibrahim et al., 2003) were used in the studies because they belong to the family of aminoalkylindole cannabinoids and produce potent peripheral antihyperalgesia in peripheral pain models (Johanek et al., 2001; Malan et al., 2003; Nackley et al., 2003). In a set of experiments, the $\mathrm{CB}_{1}$ agonist ACEA was used as a prototypical TRPV1-activating cannabinoid for comparative purposes (Price et al., 2004a). Because TRPV1 and TRPA1 play a key role in peripheral mechanisms of tissue damage-induced hyperalgesia (Caterina et al., 2000; Obata et al., 2005; Bautista et al., 2006; Kwan et al., 2006), we investigated whether WIN and AM1241 modulated CAP (a TRPV1-specific agonist) (Caterina et al., 1997) and mustard oil (MO) (a TRPA1-specific agonist) (Bandell et al., 2004; Jordt et al., 2004; Bautista et al., 2006) responses in TG neurons.

Perforated-patch voltage-clamp recording of CAP-activated currents $\left(I_{\mathrm{CAP}}\right)$ from cannabinoid- versus vehicle-treated neurons were compared with avoid interference from progressive reduction of $I_{\mathrm{CAP}}$ amplitudes (i.e., tachyphylaxis) caused by successive application of CAP (Koplas et al., 1997). The application of WIN $(25 \mu \mathrm{M})$ or AM1241 $(30 \mu \mathrm{M})$ generated responses in $70-80 \%$ of CAP-responsive small- to medium-sized neurons (15-40 $\mu \mathrm{m})$. In neurons responsive to pretreatment with either WIN or AM1241 and subsequent CAP application, an inhibition of $I_{\mathrm{CAP}}$ by 45 and $30 \%$ was detected (Fig. $1 \mathrm{~A}, \mathrm{C}$ ). In contrast, the remaining $20-30 \%$ of capsaicin-responsive neurons did not respond to pretreatment with either WIN or AM1241; in this subgroup of cells, there was no detectable change in $I_{\mathrm{CAP}}$ by the cannabinoids. In addition, pretreatment with either CAP $(0.5$ $\mu \mathrm{M})$ or the TRPV1-specific agonist ACEA $(25 \mu \mathrm{M})$ (Price et al., $2004 \mathrm{a}$ ) attenuated subsequent $I_{\mathrm{CAP}}$ by $\approx 50 \%$ in nearly all CAPresponsive neurons (Fig. $1 \mathrm{~A}, \mathrm{C}$ ). We next tested whether AM1241 and ACEA, like WIN (Patwardhan et al., 2006a), inhibit $I_{\text {CAP }}$ in a concentration-dependent manner. Treatment of neurons with the cannabinoids demonstrated that the threshold concentrations for WIN, AM1241, and ACEA to achieve statistically signif-

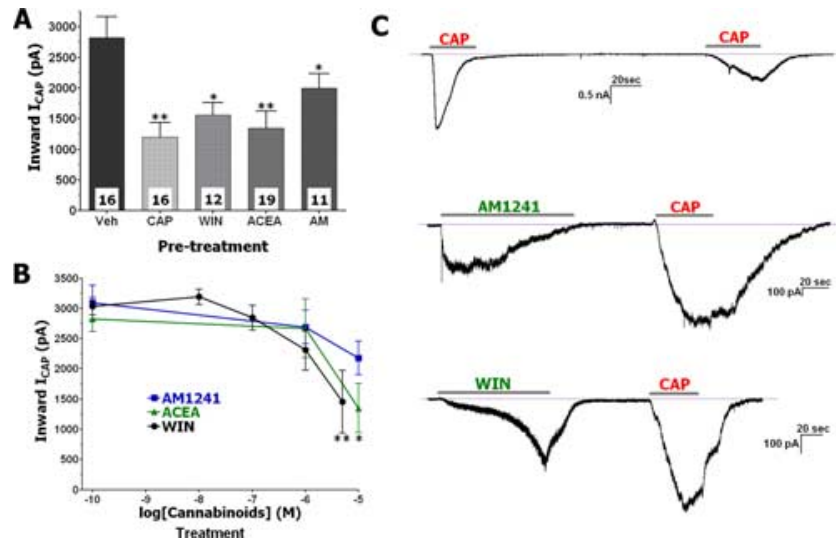

Figure 1. $\mathrm{ACEA}, \mathrm{WIN}$, and $\mathrm{AM} 1241$ inhibit /CAP $_{\text {in }} \mathrm{TG}$ neurons. $A$, $\mathrm{TG}$ neurons were pretreated with ACEA $(25 \mu \mathrm{m})$, WIN $(25 \mu \mathrm{m})$, or AM1241 $(30 \mu \mathrm{m})$, as well as CAP $(0.5 \mu \mathrm{m})$, and evaluated for desensitizing $I_{\text {CAP }}(0.5 \mu \mathrm{m}$ applied for $40 \mathrm{~s})$. Drugs were applied at an interval of $3 \mathrm{~min}$ with CAP pretreatments for $30 \mathrm{~s}$, and ACEA, WIN, and AM1241 pretreatments for 2 min. Numbers of recorded neurons are indicated within bars. $B, A C E A$, WIN, and AM1241 inhibit $I_{\text {CAP }}$ in a concentration-dependent manner. $I_{C A P}$ was plotted as a function of cannabinoid concentrations applied to neurons for $2 \mathrm{~min}$. Vehicle (0.1\% DMSO)-treated $I_{\text {CAP }}$ is at $\log [\mathrm{drug}]=-10$ point. $n=8-13$. C, Typical $I_{\text {WIN }} I_{\text {AM1241 }}$, and $I_{\text {CAP }}$ traces recorded during experiments; results of experiments are summarized on $\boldsymbol{A}$. Durations of particular drug applications are marked with horizontal bars. Data were generated from TG neurons cultured for $24-48 \mathrm{~h}$. Error bars are SEM. ${ }^{*} p<0.05 ;{ }^{* *} p<0.01$.

icant inhibition of $I_{\mathrm{CAP}}$ were 5,30 , and $10 \mu \mathrm{M}$, respectively (Fig. $1 \mathrm{~B})$. The $\mathrm{IC}_{50}$ values for WIN, AM1241, and ACEA obtained by fitting with the Hill's equation were $1.1,6.5$, and $1.27 \mu \mathrm{M}$, respectively. However, these $\mathrm{IC}_{50}$ values did not generate statistically significant inhibition. In addition to the attenuation of the magnitude of $I_{\mathrm{CAP}}$, the cannabinoids also altered the kinetics of $I_{\mathrm{CAP}}$ (Fig. 1C); approximately a fourfold increase in the duration of the $5-95 \%$ rise time for $I_{\mathrm{CAP}}$ was observed in neurons pretreated with 25-30 $\mu \mathrm{M}$ of the cannabinoids $(7.41 \pm 1.25 \mathrm{~s}, n=16$, vs $27.41 \pm$ $1.81 \mathrm{~s}, n=42$; $t$ test, $p<0.0001)$. A similar change in $I_{\mathrm{CAP}}$ kinetics during capsaicin-induced tachyphylaxis has been reported (Piper et al., 1999). Together, these results demonstrate that pretreatment of sensory neurons with WIN (Patwardhan et al., 2006a) and other cannabinoids dose-dependently inhibit $I_{\mathrm{CAP}}$ magnitude and alter the kinetics of $I_{\mathrm{CAP}}$.

Experiments evaluating desensitization of $\mathrm{MO}$-gated currents $\left(I_{\mathrm{MO}}\right)$ by the cannabinoids were conducted in a same manner. Like $I_{\mathrm{CAP}}$ tachyphylaxis in the previous set of the experiments, $I_{\mathrm{MO}}$ tachyphylaxis was used as positive control (Brand and Jacquot, 2002; Jacquot et al., 2005; Akopian et al., 2007; Ruparel et al., 2008). $I_{\mathrm{MO}}$ was detected in $67 \%$ (51 of 76 ) of small- to medium-sized neurons. A wide cell-to-cell variation in the size of $I_{\mathrm{MO}}$ and extent of $I_{\mathrm{MO}}$ tachyphylaxis was observed in individual neurons (Fig. 2 B). Pretreatment with WIN, AM1241, and ACEA (25-30 $\mu \mathrm{M})$ reduced the subsequent $I_{\mathrm{MO}}$ by 60,41 , and $47 \%$, respectively; the magnitude of these inhibitory effects are comparable with the magnitude of $I_{\mathrm{MO}}$ tachyphylaxis (Fig. 2A). However, $I_{\mathrm{MO}}$ tachyphylaxis was not apparent in $26.7 \%$ (4 of 15) of MO-responsive neurons (Akopian et al., 2007). Similarly, in $\approx 30 \%$ of neurons responsive to either WIN, AM1241, or ACEA, there was no apparent reduction in subsequent $I_{\mathrm{MO}}$ magnitude. It is also worth noting that a subset of ACEA-responsive neurons ( 8 of 24 ACEA-sensitive) did not reveal $I_{\mathrm{MO}}$ above noise. Therefore, only neurons that displayed detectable $I_{\mathrm{MO}}$ after ACEA pretreatment (i.e., 16 of 24 ACEA-sensitive) were used for additional analysis (Fig. $2 A$ ). Lower (i.e., $<25 \mu \mathrm{M}$ ) concentrations of the cannabinoids did not induce a statistically significant $I_{\mathrm{MO}}$ inhibi- 

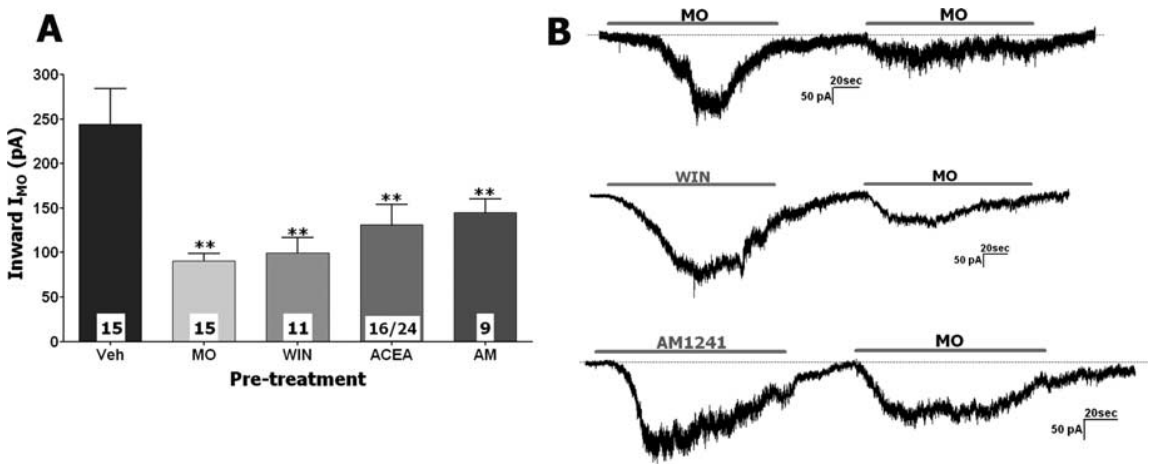

Figure 2. ACEA, WIN, and AM1241 inhibit MO $_{M 0}$ in TG neurons. $A$, Pretreatment of TG neurons with ACEA $(25 \mu \mathrm{M}), \operatorname{WIN}(25 \mu \mathrm{M})$, or AM1241 $(30 \mu \mathrm{M})$, as well as $\mathrm{MO}(50 \mu \mathrm{M})$, desensitize $I_{\mathrm{MO}}(50 \mu \mathrm{m}$ applied for $2 \mathrm{~min})$. Drugs were applied at an interval of $3 \mathrm{~min}$ with MO, ACEA, WIN, and AM1241 pretreatments for 2 min. Numbers of recorded neurons are indicated within bars. $\boldsymbol{B}$, Typical $I_{\text {WIN }} I_{\text {AM1241 }}$, and $I_{\text {MO }}$ traces recorded during experiments represented on $A$. Durations of particular drug applications are marked with horizontal bars. Data were generated from TG neurons cultured for $24-48 \mathrm{~h}$. Error bars are SEM. ${ }^{* *} p<0.01$.
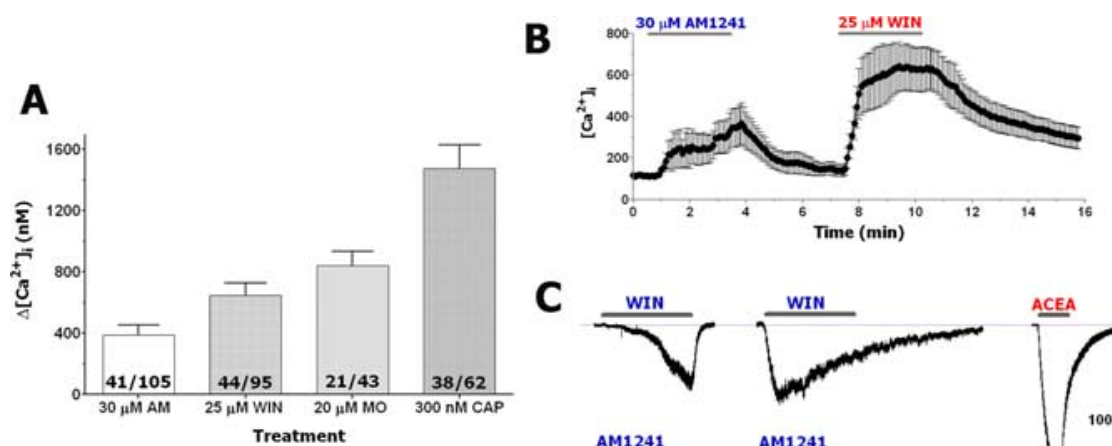

C
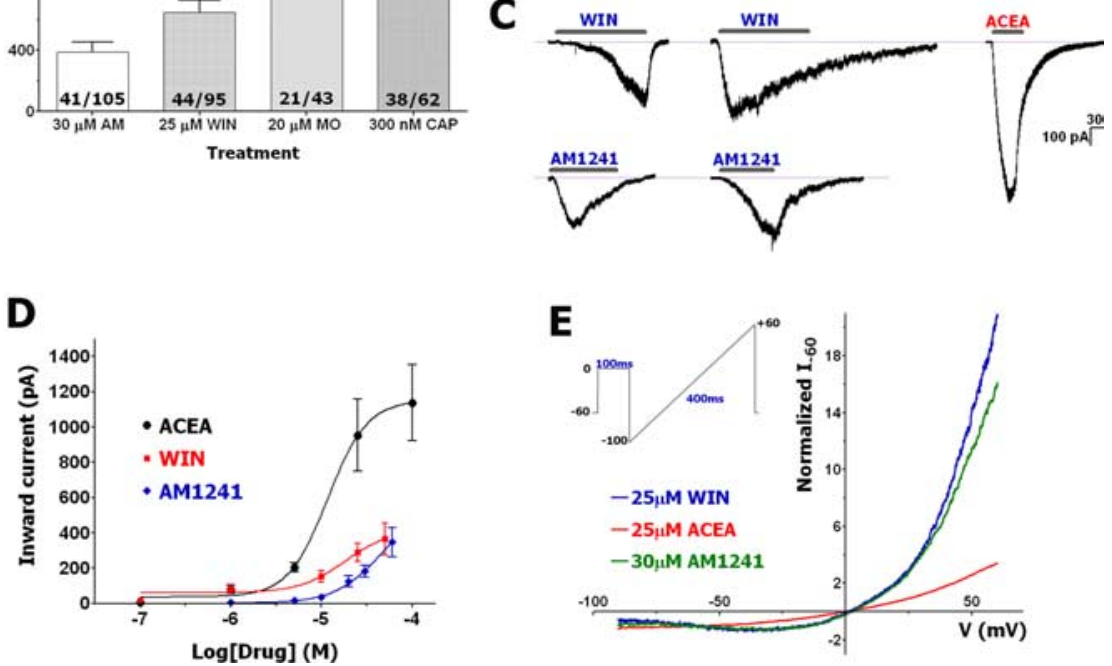

Figure 3. WIN and AM1241 activate $\mathrm{Ca}^{2+}$-permeable, nonselective currents in subsets of TG neurons. $A$, Application of indicated concentrations of AM1241 (AM), WIN, M0, and CAP trigger $\left[\mathrm{Ca}^{2+}\right]_{i}$ accumulation in subset of TG neurons. Numbers of analyzed (numerator) and total recorded (denominator) neurons are indicated within bars. CAP was applied for 1 min, whereas MO, WIN, and AM1241 were applied for $3 \mathrm{~min}$. B, Characteristic $\mathrm{Ca}^{2+}$-imaging traces from $n=10 \mathrm{TG}$ neurons that responded to both AM1241 and WIN. Application durations are noted by horizontal bars. C, Typical whole-cell fast and slow inward currents in TG neurons generated by AM1241 $(30 \mu \mathrm{M})$, WIN $(25 \mu \mathrm{M})$, and ACEA $(25 \mu \mathrm{M})$. The currents were acquired from separate neurons bathed in SES $\left(2 \mathrm{mM} \mathrm{Ca}^{2+}\right)$ (see Materials and Methods for buffer compositions). $\boldsymbol{D}$, Concentration-response curves for $I_{\text {WIN }}$ $I_{\text {ACEA }}$ and $I_{\text {AM1241 } 1}$. Data for each point were generated from separate neurons by application of cannabinoids for 2 min. $n=6-18$. Whole-cell recordings were performed with SES and SIS. $E, I-V$ relationships (averaged from $4-8$ traces) for $I_{\text {AM1241 }}, I_{\text {WIN }}$, and $I_{\text {ACEA }}$ were obtained by recording from neurons maintained in a $\mathrm{Mg}^{2+}$-free SES physiological solution with $2 \mathrm{mM} \mathrm{Ca}^{2+}$. The electrodes were filled with $\mathrm{Cs}$-containing SIS without $\mathrm{Mg}^{2+} . \mathrm{I}-V$ curves were recorded from separate neurons. Depolarizing voltage ramp protocol is presented in the inset. TG neurons were cultured for $24-48 \mathrm{~h}$. Error bars are SEM. ${ }^{* *} p<0.01$.

tion, although $10 \mu \mathrm{M}$ WIN and ACEA showed a trend in $I_{\mathrm{MO}}$ suppression (data not shown). Unlike cannabinoid-induced changes in $I_{\text {CAP }}$ kinetics, there was no significant difference in the $5-95 \%$ rise time of $I_{\mathrm{MO}}$ after $\mathrm{MO}$ or cannabinoid versus vehicle pretreatment (vehicle treatment, $42.6 \pm 8.5 \mathrm{~s}, n=16$, vs $\mathrm{MO} /$ cannabinoid treatment, $45.1 \pm 5.2 \mathrm{~s}, n=51$ ). Together, our data suggest that the cannabinoid agonists WIN ( $>5$ or $25 \mu \mathrm{M}$ for $I_{\mathrm{MO}}$ ) and AM1241 (>30 $\mu \mathrm{M})$ as well as TRPV1-gating ACEA $(>10$ or $25 \mu \mathrm{M}$ for $I_{\mathrm{MO}}$ ) are able to desensitize/ inhibit $I_{\mathrm{CAP}}$ and $I_{\mathrm{MO}}$ in a concentrationdependent manner in a subset of TG neurons.

WIN and AM1241 activate nonselective $\mathrm{Ca}^{2+}$-permeable channels in

\section{TG neurons}

We recently demonstrated that inhibition of $I_{\mathrm{CAP}}$ by WIN in rat TG sensory neurons was independent of G-protein-coupled receptors, occurred at low micromolar concentrations of WIN (Figs. 1, 2), and was $\mathrm{Ca}^{2+}$ dependent (Patwardhan et al., 2006a). Moreover, the inhibitory concentrations of WIN, AM1241, and ACEA exceed those concentrations required to fully activate metabotropic cannabinoid receptors such as $\mathrm{CB}_{1}$ and $\mathrm{CB}_{2}$ (Malan et al., 2001; Piomelli, 2003). Importantly, the attenuation of $I_{\mathrm{CAP}}$ and $I_{\mathrm{MO}}$ required activation (i.e., inward current generation) of TG neurons by WIN, AM1241, and ACEA treatments (Figs. 1C, 2B). Therefore, to understand the potential molecular mechanisms of the cannabinoid-induced inhibition of $I_{\mathrm{CAP}}$ and $I_{\mathrm{MO}}$ in sensory neurons, we sought to characterize the basic properties of WIN and AM1241 responses in TG neurons.

We first used calcium imaging to investigate TG neurons responding to WIN and AM1241 applications. Figure $3 A$ shows that treatment of neurons with inhibitory concentrations of WIN and AM1241 (i.e., 25-30 $\mu \mathrm{M}$ ) (Figs. 1 A, 2A) evoked a robust accumulation of $\left[\mathrm{Ca}^{2+}\right]_{\mathrm{i}}$ in $\sim 40-45 \%$ of tested neurons. In comparison, MO- and CAP-evoked increases in $\left[\mathrm{Ca}^{2+}\right]_{i}$ were detected in 49 and $61 \%$ of analyzed neurons, respectively (Fig. 3A). WIN and AM1241 responses extensively $(75 \%)$ coincided in the same neuronal population (Fig. 3B), although occasional AM1241-positive/ WIN-negative neurons and vice versa were observed. The subset of AM1241-positive/ WIN-negative neurons are primarily large diameter $(>50 \mu \mathrm{m})$ neurons.

Next, we used whole-cell voltage-clamp recording to characterize the basic properties of WIN- and AM1241-gated currents $\left(I_{\mathrm{WIN}}\right.$ and $\left.I_{\mathrm{AM} 1241}\right)$ in TG neurons and to compare them with $I_{\mathrm{ACEA}}$ features. The application of either agonist at the indicated concentrations (Fig. 3C,D) elicited inward currents in subsets of small- to medium-sized neurons [overall, 143 of 243 (59\%) for WIN and 58 of 106 (55\%) for AM1241]. In some experiments, recordings were performed with a K-gluconate pipette solution and the results indicated that the $I_{\mathrm{WIN}}$ and $I_{\mathrm{AM} 1241}$ are cationselective (data not shown). The generation of $I_{\mathrm{WIN}}$ and $I_{\mathrm{AM} 1241}$ 
was restricted to CAP-sensitive neurons. Moreover, $\sim 80 \%$ of tested neurons producing $I_{\mathrm{CAP}}$ also generated $I_{\mathrm{WIN}}$ or $I_{\mathrm{AM} 1241}$. The exposure of neurons to WIN, AM1241, and ACEA produced concentration-dependent current responses that were fitted with the Hill equation. The analysis yielded the following parameters: $\quad \mathrm{EC}_{50}$ (in micromolar concentration) and $h$ for WIN $(18 ; 1.7)$, AM1241 (48; 1.65), and ACEA $(12 ; 2.0)$. Maximal currents $\left(I_{\max }\right)$ were $365.9 \pm 90.9$ pA $(n=15)$ for WIN $(50 \mu \mathrm{M}), 347.7 \pm$ $81.9 \mathrm{pA}(n=28)$ for AM1241 $(60 \mu \mathrm{M})$, and $1137 \pm 215.8 \mathrm{pA}(n=9)$ for ACEA $(100$ $\mu \mathrm{M}$ ) (Fig. $3 D$ ). Figures $1 C, 2 B, 3 C$, and 7 , $B-D$, indicate that $I_{\mathrm{WIN}}$ and $I_{\mathrm{AM} 1241}$ displayed complicated kinetics that neither fitted with exponential functions, nor demonstrated uniform activation curves. Thus, $I_{\text {WIN }}$ displayed a slow activation kinetic $(5-95 \%$ rise time of $45.8 \pm 3.0 \mathrm{~s}, n=$ 53 ) sometimes with a delayed rise and little-to-no acute desensitization in the majority of analyzed neurons, whereas $I_{\mathrm{AM} 1241}$ tended to be faster as measured by both activating (15.6 $\pm 2.7 \mathrm{~s}, n=24)$ and desensitizing time courses (Fig. $3 C$ ). We next examined current-voltage $(I-V)$ relationships of $I_{\mathrm{WIN}}$ and $I_{\mathrm{AM} 1241}$ in sensory neurons. In physiological solution (i.e., SES), the $I-V$ relationships for $I_{\mathrm{WIN}}$ and $I_{\mathrm{AM} 1241}$ exhibited a reversal potential close to $0 \mathrm{mV}$ (Fig. $3 E$ ) and pronounced outward rectification with a ratio $\left(I_{+60} / I_{-60}\right)$ of 12 for WIN and 11 for AM1241 (Fig. $3 E$ ). These rectification ratios were larger than the ratio of 3 observed for ACEA. Together, the presented results suggest that WIN and AM1241 likely activate a nonselective $\mathrm{Ca}^{2+}$-permeable cation channel.

WIN and AM1241 activate the TRPA1 channel and inhibit CAP and MO responses in a heterologous expression system To identify the channels generating $I_{\mathrm{WIN}}$ and $I_{\mathrm{AM} 1241}$, we examined the responsiveness of various TRP channels expressed in CHO cells to WIN and AM1241. CHO cells expressing TRPV1, TRPV2, TRPV3, TRPV4, or TRPM8 were not activated by WIN, but responded to control stimuli such as CAP, 2-APB (2aminoethoxydiphenyl borane), $4 \alpha$-PDD ( $4 \alpha$-phorbol 12,13didecanoate), and icilin (supplemental Fig. $1 A-C$, available at www.jneurosci.org as supplemental material) (McKemy et al., 2002; Watanabe et al., 2002; Hu et al., 2004). Our recently published data demonstrated that WIN-induced dephosphorylation of TRPV1 could be mediated by the TRPA1 channel (Jeske et al., 2006). Therefore, we applied WIN and AM1241 to CHO cells expressing the TRPA1 channel, which has been originally reported as a mechano/cold-gated channel (Story et al., 2003; Bandell et al., 2004; Corey et al., 2004). Figure 4 illustrates that WIN and AM1241, but not ACEA, activate TRPA1-expressing CHO cells, whereas untransfected, vector- (i.e., pcDNA5/FRT), green fluorescent protein- (GFP), or TRPV1-transfected CHO cells showed no appreciable currents.

Overall, WIN $(25 \mu \mathrm{M})$ and AM1241 $(30 \mu \mathrm{M})$ generated a similar magnitude of current in sensory neurons $\left(I_{\mathrm{WIN}}=-290.1 \pm\right.$ $\left.50.62 \mathrm{pA}, n=28 ; I_{\mathrm{AM} 1241}=-189.1 \pm 34.29 \mathrm{pA}, n=30 \mathrm{vs} \mathrm{NS}\right)$. However, in TRPA1-expressing $\mathrm{CHO}$ cells, $I_{\text {WIN }}$ was 10 -fold larger than $I_{\mathrm{AM} 1241}\left(I_{\mathrm{WIN}}=76.3 \pm 8.5 \mathrm{pA} / \mathrm{pF}, n=17\right.$, vs $I_{\mathrm{AM} 1241}$ $=7.33 \pm 1.2 \mathrm{pA} / \mathrm{pF}, n=14 ; t$ test, $p<0.0001$ ) (Fig. 4 ). Because TRPA1 expression is exclusively restricted to a subset of TRPV1positive neurons (Jordt et al., 2004; Kobayashi et al., 2005; Obata et al., 2005; Diogenes et al., 2007) and NGF (100 ng/ml) treatment of sensory neurons results in a substantial increase in TRPA1-positive neurons within a TRPV1-expressing subset (Diogenes et al., 2007), we characterized $I_{\mathrm{WIN}}$ and $I_{\mathrm{AM} 1241}$ in TRPA1-TRPV1-coexpressing CHO cells. In these cells, the similarity in the magnitude of $I_{\mathrm{WIN}}$ and $I_{\mathrm{AM} 1241}$ observed in sensory neurons was restored $\left(I_{\mathrm{WIN}}=17.4 \pm 2.6 \mathrm{pA} / \mathrm{pF}, n=15\right.$, vs $\left.I_{\mathrm{AM} 1241}=12.1 \pm 4.7 \mathrm{pA} / \mathrm{pF}, n=12\right)($ Fig. 4$)$. This unique selectivity of AM1241 is consistent with the hypothesis that TRPA1 and TRPV1 may interact in sensory neurons (McMahon and Wood, 2006; Akopian et al., 2007). Together, our data indicate that WIN and AM1241 are able to activate TRPA1, and that optimal current activation by AM1241, similar in magnitude to that observed in sensory neurons, was only observed in CHO cells cotransfected with TRPA1 and TRPV1.

We next evaluated whether the attenuation of $I_{\mathrm{CAP}}$ and $I_{\mathrm{MO}}$ induced by application of WIN, AM1241, and ACEA could be reproduced in the heterologous expression system. All tested cannabinoids significantly inhibited both $I_{\mathrm{CAP}}$ and $I_{\mathrm{MO}}$ in CHO cells transfected with both TRPA1 and TRPV1 (Fig. 5A,C). The positive controls consisted of CAP- and MO-induced tachyphylaxis in these experiments (Koplas et al., 1997; Akopian et al., 2007; Ruparel et al., 2008). To further demonstrate the involvement of the TRPA1 channel in cannabinoid inhibition of $I_{\mathrm{CAP}}$ and $I_{\mathrm{MO}}$, the modulation of CAP and MO responses were studied in the TRPV1 or TRPA1 expression systems, respectively. Figure $5 B$ shows that only the TRPV1-gating cannabinoid agonist ACEA, but not WIN and AM1241, attenuated $I_{\text {CAP }}$ in CHO cells containing TRPV1. In contrast, in TRPA1-expressing CHO cells, only WIN and the control stimulus $\mathrm{MO}$ exerted a profound inhibition of $I_{\mathrm{MO}}$ (Fig. $5 C$ ). The application of AM1241 (30 $\left.\mu \mathrm{M}\right)$, like ACEA, 

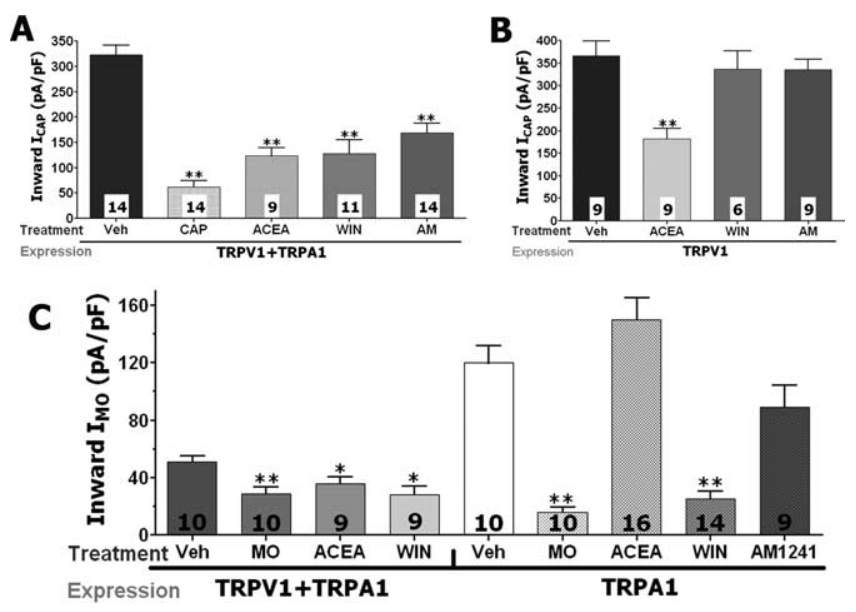

Figure 5. WIN and AM1241 desensitize $I_{C A P}$ and $I_{M 0}$ in TRPV1-and/or TRPA1-expressing $\mathrm{CHO}$ cells. A, WIN $(25 \mu \mathrm{m})$, ACEA $(25 \mu \mathrm{m})$, and AM1241 $(30 \mu \mathrm{m})$ as well as CAP $(0.3 \mu \mathrm{M})$ inhibit CAP $_{\text {CAP }}$ $(0.3 \mu \mathrm{M})$ in TRPV1/TRPA1-expressing CH0 cells. $\boldsymbol{B}$, TRPV1-gating ACEA, but not TRPA1-gating WIN and AM1241 attenuates $I_{\text {CAP }}(0.3 \mu \mathrm{m})$ in TRPV1-expressing CHO cells. C, ACEA and WIN (25 $\mu \mathrm{m}$ each), as well as M0 $(50 \mu \mathrm{M})$, inhibit $I_{\mathrm{MO}}(50 \mu \mathrm{m})$ in TRPA1-TRPV1-expressing $\mathrm{CHO}$ cells, whereas only TRPA1-gating agonists WIN and M0 still show inhibition of $I_{\text {MO }}$ in TRPA1expressing $\mathrm{CHO}$ cells. CHO cells were treated 2 min with MO, ACEA, WIN, and AM1241, and $30 \mathrm{~s}$ with CAP. $I_{\text {CAP }}$ were recorded by CAP application during $40 \mathrm{~s}$, whereas $M 0$ was applied for 2 min to record $I_{M O}$. The interval between treatment and $I_{M 0}$ or $I_{\text {CAP }}$ registration was $3 \mathrm{~min}$. The numbers of responsive $\mathrm{CHO}$ cells are shown inside the bars. Error bars are SEM. ${ }^{*} p<0.05$; ${ }^{* *} p<0.01$.

did not produce a substantial inhibition of $I_{\mathrm{MO}}$ in TRPA1expressing system (Fig. 5C). This effect could be attributable to the small magnitude of $I_{\mathrm{AM} 1241}$ developed in the TRPA1expressing system (Fig. 4). Together, our results suggest that, at least in the heterologous expression systems, WIN-induced inhibition of $I_{\mathrm{CAP}}$ and $I_{\mathrm{MO}}$ require the expression of TRPA1. In addition, the effective AM1241-triggered attenuation of these currents can be achieved only in $\mathrm{CHO}$ cells coexpressing both TRPA1 and TRPV1.

\section{WIN and AM1241 inhibitory effects on $I_{\mathrm{CAP}}$ in the sensory neurons are mediated via the TRPA1 channel}

Although the results presented demonstrate that TRPA1 is essential for the attenuation of $I_{\mathrm{CAP}}$ by WIN and AM1241 in the heterologous expression system, it does not establish a similar role of the TRPA1 channel in sensory neurons. To address this question, we used the siRNA approach to functionally silence TRPA1 in the sensory neurons (Hannon and Rossi, 2004; Juliano et al., 2005). We evaluated siRNA against TRPA1 using controls including negative siRNA control [scrambled no. 1 siRNA from Ambion and $A D r$ siRNA against the Drosophila homolog of TRPA1 (Rosenzweig et al., 2005)], target specificity evaluation, multiple active siRNAs, and low siRNA concentrations (Jeske et al., 2006).

We first observed that the HiPerFect reagent neither significantly modified CAP nor MO responses in TG neurons (Fig. $6 A, B)$ nor changed TRPA1 protein level (Jeske et al., 2006). Then, different siRNAs against TRPA1 were evaluated for their ability to suppress TRPA1 function (i.e., MO response) in TG neurons. Figure $6 \mathrm{~A}$ illustrates that all three siRNAs against TRPA1 significantly inhibited MO responses and that ALab was the most effective silencer of TRPAl function. Moreover, the efficiency of $A L a b$ in TRPA1 silencing ( $\approx 90 \%)$ was especially apparent when only data from transfected neurons were taken into account (Fig. 6A; bar ALab-Transf, transfected neurons identified by Alexa Fluor 488-coupled siRNA). The negative con- trol siRNAs ( $A D r$ and scrambled no. 1) did not significantly alter MO responses. In addition, $A L a b$ as well as $A D r$ siRNA did not impair CAP responses in TG neurons (i.e., target specificity control) (Fig. 6B, $G$ ). Finally, in our previous publication, we evaluated the ability of $A L a b$ to attenuate TRPA1 protein production using a verified and affinity-purified anti-TRPA1 antisera (Jeske et al., 2006). In addition, control siRNAs (i.e., scrambled no. 1 and $A D r$ ) did not affect either TRPA1 or TRPV1 expression (Jeske et al., 2006).

The verified $A L a b$ and $A D r$ (as a negative control) siRNAs were next used to examine the potential role of TRPA1 in mediating WIN and AM1241 responses in TG neurons. Transfected neurons were processed for calcium imaging (Fig. 6G). The ALab siRNA was equally effective (by $80-90 \%$ ) in knocking down WIN- and MO-evoked $\left[\mathrm{Ca}^{2+}\right]_{\mathrm{i}}$ accumulation in TG neurons (Fig. 6A,D). However, pretreatment with $A L a b$ siRNA only partially blocked AM1241-induced responses in TG neurons (Fig. $6 C)$. Interestingly, a portion of transfected large-diameter neurons still exhibited substantial AM1241-trrigered $\mathrm{Ca}^{2+}$ influx. In contrast, AM1241 generated $\mathrm{Ca}^{2+}$ influx was nearly abolished in transfected small- to medium-diameter neurons, although a small subset $(\approx 20 \%)$ continued to exhibit a slight $\left[\mathrm{Ca}^{2+}\right]_{\mathrm{i}}$ accumulation (50-150 nM). In addition, ALab transfected TG neurons very rarely $(<10 \%)$ exhibited any WIN-activated rise in $\left[\mathrm{Ca}^{2+}\right]_{\mathrm{i}}$. To confirm these data, we tested MO- and WINinduced accumulation of $\left[\mathrm{Ca}^{2+}\right]_{i}$ in sensory neurons from wildtype and TRPA1 null-mutant mice (Kwan et al., 2006). In agreement with published data (Bautista et al., 2006), MO $(50 \mu \mathrm{M})$ responses were not detected in sensory neurons from TRPA1 null-mutant mice, whereas CAP (50 nM) was still able to induce accumulation of $\left[\mathrm{Ca}^{2+}\right]_{i}$ in both wild-type and TRPA1 KO mouse sensory neurons (Fig. 6E). We next used sensory neurons from wild-type and TRPA1 null-mutant mice to examine WINtriggered responses. Figure $6 \mathrm{~F}$ demonstrate that only 1 cell of 80 revealed a WIN response above background (120 nM accumulation in $\left[\mathrm{Ca}^{2+}\right]_{\mathrm{i}}$ ). Together, our results indicate that WIN responses in sensory neurons are specifically and exclusively mediated by the TRPA1 channel. In addition, the TRPA1 channel also contributes to AM1241-evoked responses in small-diameter, but not large-diameter, sensory neurons.

Because TRPA1 mediates WIN- and AM1241-induced increases in $\left[\mathrm{Ca}^{2+}\right]_{\mathrm{i}}$ within small- to medium-diameter TG neurons, we used the siRNA-based knockdown of TRPA1 to evaluate whether this channel contributes to WIN- and AM1241-induced inhibition of $I_{\mathrm{CAP}}$ in TG neurons. Because recordings of $I_{\mathrm{CAP}}$ were performed within $72 \mathrm{~h}$ after transfection, we performed characterization of the longevity of functional TRPA1 suppression (Jeske et al., 2006). Although the effects of siRNA were slightly diminished (by $10-20 \%$ ) at $72 \mathrm{~h}$ after transfection, a significant inhibition of TRPA1 function persists under these conditions (Jeske et al., 2006). Perforated-patch $I_{\mathrm{CAP}}$ recordings of vehicle-, CAP-, WIN-, or AM1241-treated neurons were obtained from mock, $A D r$, or $A L a b$ siRNA transfected neurons at $48-72 \mathrm{~h}$ after transfection. In neurons exposed to no-siRNA (i.e., mock) or $A D r$, the application of WIN, AM1241, and CAP (as a positive control) produced a substantial inhibition of $I_{\mathrm{CAP}}($ Fig. $7 A-C)$. Moreover, $I_{\mathrm{WIN}}(25 \mu \mathrm{M})$ magnitudes were $306.4 \pm 86.3 \mathrm{pA}(n=$ $15)$ in mock- and $317.6 \pm 108.6 \mathrm{pA}(n=12)$ in $A D r$-transfected neurons (Fig. $7 B, C$ ). In contrast, neurons in which $A L a b$ labeling was detected exhibited a $\approx 90 \%$ reduction in $I_{\text {WIN }}(29.6 \pm 5.5 \mathrm{pA}$ in 6 of 22 neurons), with no current detected in 16 of 22 recorded neurons (Fig. $7 D$, top panel). $I_{\mathrm{AM} 1241}$ silencing in ALab transfected neurons was also substantial $(\approx 60 \%)$, but not as pro- 
nounced as for $I_{\text {WIN }}$ (Fig. $7 D$, bottom panel). Importantly, neither AM1241 nor WIN attenuated $I_{\text {CAP }}$ magnitudes in ALabsiRNA transfected TG neurons, whereas CAP still produced a substantial tachyphylaxis (Fig. $7 A, D$ ). Collectively, these data demonstrate that TRPA1 mediates WINevoked $\left[\mathrm{Ca}^{2+}\right]_{\mathrm{i}}$ accumulation and $I_{\mathrm{WIN}}$ generation in TG neurons; TRPA1 partially conducts AM1241 responses in TG neurons; and the TRPA1 channel is critically required for WIN- and AM1241-induced inhibition/desensitization of $I_{\mathrm{CAP}}$ in adult rat TG neurons.

\section{Peripheral doses of AM1241 and WIN attenuate capsaicin-induced nociception in wild-type, but not in TRPA1 null- mutant mice}

Selective and specific antagonists for the TRPA1 channel have not been developed. Therefore, to evaluate the in vivo relevance of the proposed mechanism, we performed a set of in vivo nocifensive behavioral assays in wild-type (WT) and TRPA1 knock-out mice (TRPA1 KO). Because peripheral effects of WIN and AM1241 have not been studied in B6129P1/F2J mice, we first evaluated doses of cannabinoids capable of producing peripherally restricted inhibition of capsaicin responses in B6129P1/F2 J (Fig. $8 A-C$ ) as well as $\mathrm{C} 57 \mathrm{BL} / 6 \mathrm{~J}$ mice (supplemental Fig. 2, available at www. jneurosci.org as supplemental material) that have been used for generation of $\mathrm{CB}_{1}$ and $\mathrm{CB}_{2} \mathrm{KO}$ mouse lines. Grooming and flinching of the injected paw for the first 5 min was collected as a measure of nocifensive behavior (Caterina et al., 2000; Bautista et al., 2006; Kwan et al., 2006). To evaluate the site of action, either vehicle or the given concentration of cannabinoids were injected into the contralateral hindpaw, and CAP $(0.5 \mu \mathrm{g})$ was injected into the ipsilateral hindpaw. In the WT animals, the injection of $2.5 \mu \mathrm{g}$ of WIN produced a peripherally restricted antinocifensive effect, whereas doubling the dose to $5 \mu \mathrm{g}$ produced a systemically mediated antinocifensive effect (Fig. 8A, B,D,E). This dose of WIN $(2.5 \mu \mathrm{g})$ also produced peripherally restricted effects in $\mathrm{C} 57 \mathrm{BL} / 6 \mathrm{~J}$ mice (supplemental Fig. 2C, available at www.jneurosci.org as supplemental material). The same types of experiments revealed that 40 $\mu \mathrm{g}$ of AM1241, but not $60 \mu \mathrm{g}$ (data not shown), evokes peripherally mediated antinocifensive effects in both B6129P1/F2J (Fig. $8 C, F$ ) and $\mathrm{C} 57 \mathrm{BL} / 6 \mathrm{~J}$ mice (supplemental Fig. $2 \mathrm{~A}$, available at www.jneurosci.org as supplemental material). These control experiments provide a unique opportunity to determine the role of TRPA1 in peripheral versus systemic antinocifensive actions of cannabinoids.

Using this approach, we next evaluated the peripheral WIN inhibition of CAP-induced nocifensive behavior in WT versus TRPA1 KO mice. Centrally mediated WIN ( $5 \mu \mathrm{g})$ inhibition of CAP-induced nocifensive behavior was not affected in TRPA1 null-mutant mice (Fig. $8 D$ ). However, as shown in Figure $8 E$, a peripherally restricted WIN dose $(2.5 \mu \mathrm{g})$ significantly inhibited CAP-induced nocifensive behavior by $33 \%$ in WT mice, but was
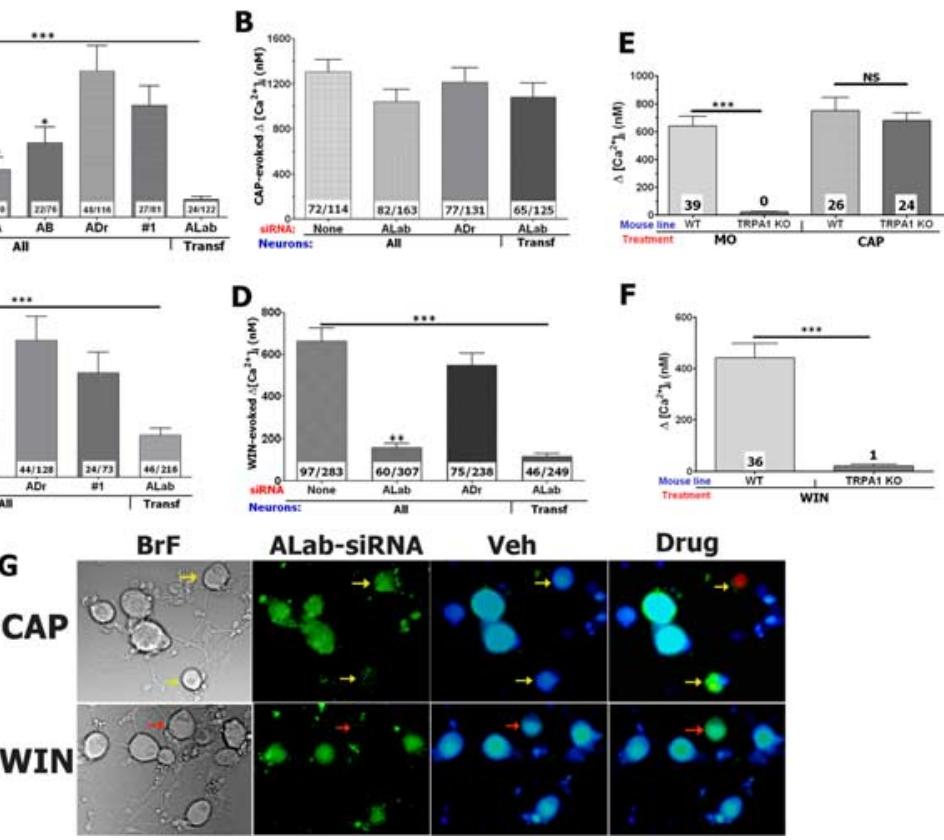

Figure 6. The TRPA1 channel mediates WIN and AM1241 responses in TG neurons. $\boldsymbol{A}-\boldsymbol{D}$, Knockdown of TRPA1 in TG neurons with rat TRPA1-specific siRNAs ALab, AA, or AB oblates positive control (M0 $20 \mu \mathrm{M})$ responses $(\boldsymbol{A})$, as well as AM1241 (30 $\mu \mathrm{M} ; \boldsymbol{C}$ and 1241 for 4 min each. Types of siRNA transfection are indicated on $x$-axis. Data were collected from all neuron indicates a neuron that is untransfected and activated by WIN, whereas transfected neurons are unresponsive to WIN application. Error bars are SEM. ${ }^{* *} p<0.01 ;{ }^{* * *} p<0.001$.

completely abolished in TRPA1 KO mice. These findings demonstrate that TRPA1 is required for mediating the peripheral, but not central, mechanism of WIN-induced antinocifensive effects. Because AM1241 also suppresses CAP responses in sensory neurons via activation of the TRPA1 channel, we next examined the effects of AM1241 on CAP-induced nocifensive behavior in WT and TRPA1 KO mice. The hindpaws of WT as well as TRPA1KO mice were treated locally with either vehicle or a peripherally restricted dose of AM1241. The injection of AM1241 at a peripherally restricted dose $(40 \mu \mathrm{g})$ (Fig. $8 C$ ) significantly inhibited CAP-induced nocifensive behavior by $35 \%$ in WT mice and this effect was abolished in TRPA1 KO mice (Fig. $8 F$ ). These results show that the peripheral antinocifensive effects of AM1241 are mediated via TRPA1.

\section{Discussion}

\section{TRPA1 mediates WIN and AM1241 inhibitory actions in} sensory neurons

The main result of the present study is the finding that certain cannabinoids such as WIN and AM1241 inhibit the responses of TG neurons to noxious chemical stimuli (CAP and MO) via activation of the TRPA1 channel in sensory neurons. Moreover, the TRPA1 channel mediates the peripheral mechanism of cannabinoid inhibition of CAP-induced nocifensive responses.

Using the heterologous expression system and the siRNA- 
A
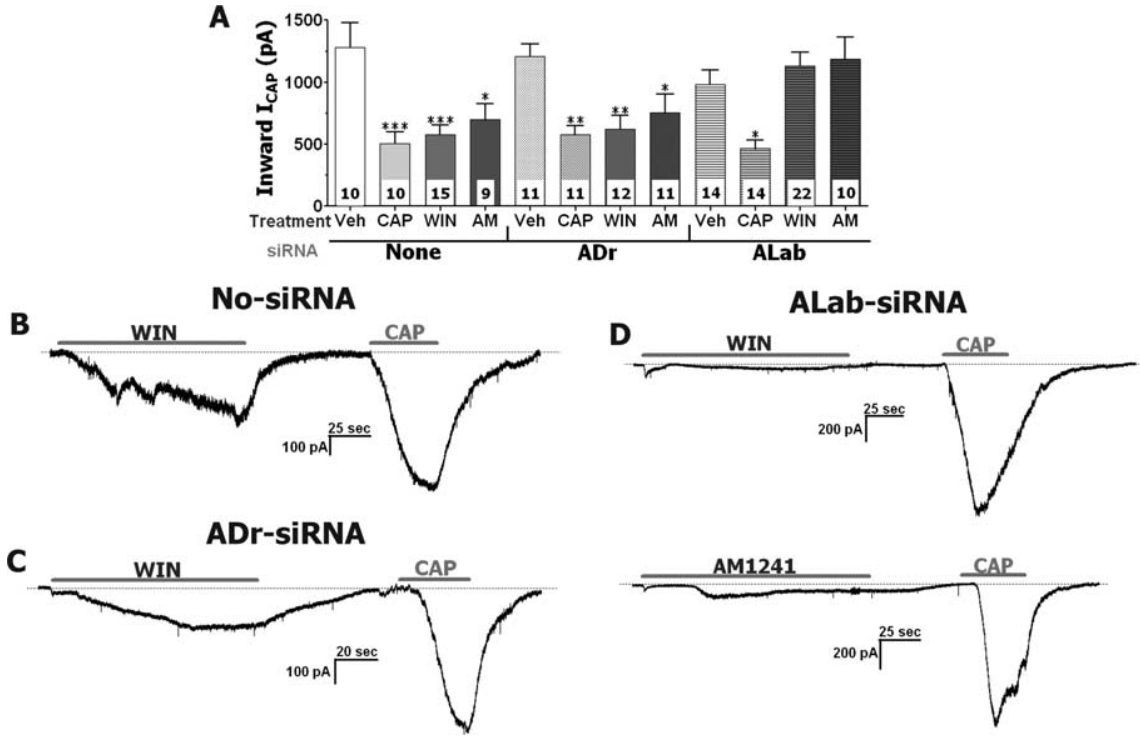

Figure 7. The TRPA1 channel mediates WIN- and AM1241-induced inhibitions of $I_{\text {CAP }}$ in TG neurons. $A$, Oblation of TRPA1 function with ALab-siRNA, but not mock and ADr-siRNA, transfections reversed inhibitory effects of WIN ( $25 \mu \mathrm{M}$ ) and AM1241 (30 $\mu \mathrm{M})$, but not $\mathrm{CAP}(0.3 \mu \mathrm{M})$, on $I_{\text {CAP }}(0.3 \mu \mathrm{M})$ in TG neurons. TG neurons were treated 2 min with WIN and AM1241, and $30 \mathrm{~s}$ with CAP. $I_{\text {CAP }}$ were generated by $40 \mathrm{~s}$ application of CAP. Interval between treatments and $I_{\text {CAP }}$ recording was 3 min. The numbers of analyzed TG neurons are shown inside the bars. One round of siRNA transfection was used. TG neurons were cultured for $3 \mathrm{~d}$. $\boldsymbol{B}-\boldsymbol{D}$, $I_{\text {WIN }} I_{\text {AM1241 }}$, and $I_{\text {CAP }}$ traces recorded during experiments on mock $(\boldsymbol{C}), \operatorname{ADr}(\boldsymbol{D})$, and ALab (E) siRNA-transfected TG neurons. Durations of particular drug applications are marked with horizontal bars.
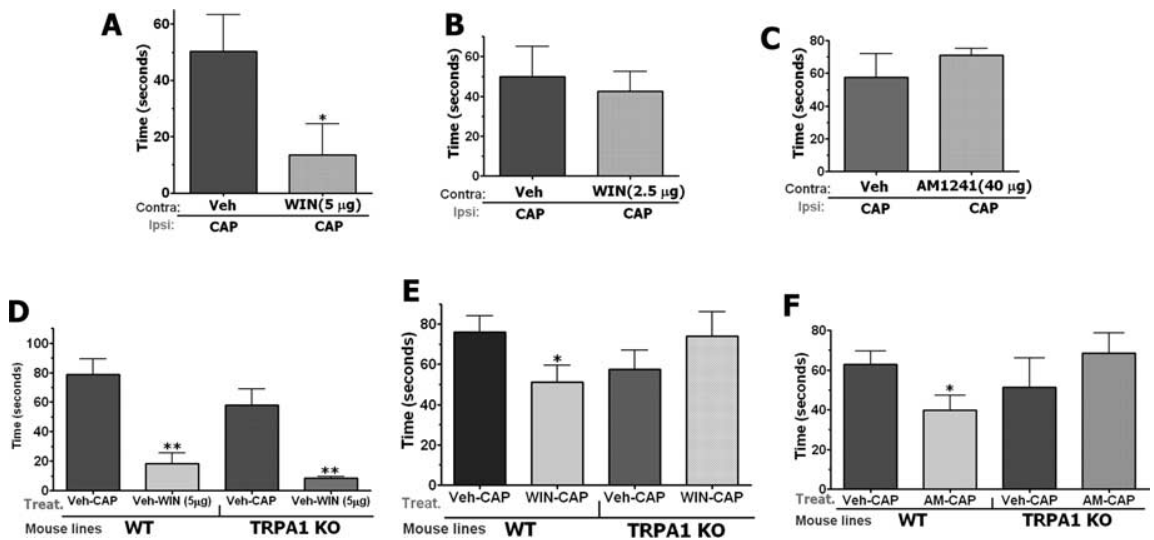

Figure 8. Effect of WIN 55,212 and AM1241 on CAP-induced nocifensive behavior in WT and TRPA1 K0 mice. All behavioral tests were performed on male mice. Behavior was measured by observers blinded to treatment allocation, and outcome of nocifensive behavior was measured as a grooming or flinching. Numbers of animals $(n)$ used for each bar of the bar graphs are indicated. $\boldsymbol{A}, \boldsymbol{B}$, Evaluation of the effect of injection of vehicle or $5 \mu \mathrm{g}(\boldsymbol{A})$ or $2.5 \mu \mathrm{g}(\boldsymbol{B})$ in the contralateral paw (Contra) to desensitize CAP-induced nocifensive behavior in ipsilateral (Ipsi) hindpaw of WT mice. $n=6-8$ (for $\boldsymbol{A}$ and $\boldsymbol{B})$. C, Evaluation of the effect of preinjection of vehicle or AM1241 (40 $\mu \mathrm{g}$ ) in the contralateral paw (Contra) to desensitize CAP-induced nocifensive behavior in ipsilateral (Ipsi) hindpaw of WT mice. $n=8-12$. D, Role of the TRPA1 channel in central mechanisms of WIN-induced antinociception. Evaluation of the effect of injection of vehicle and CAP $(0.5 \mu \mathrm{g})$ or WIN $(5 \mu \mathrm{g})$ and $\operatorname{CAP}(0.5 \mu \mathrm{g})$ in the ipsilateral paw (Ipsi) to desensitize CAP-induced nocifensive behavior in WT and TRPA1 K0 mice. $n=6$. $\boldsymbol{E}$, Role of the TRPA1 channel in peripheral mechanisms of WIN-induced antinociception Evaluation of the effect of injection of vehicle and CAP $(0.5 \mu \mathrm{g})$ or WIN $(2.5 \mu \mathrm{g})$ and CAP $(0.5 \mu \mathrm{g})$ in the ipsilateral paw (Ipsi) to desensitize CAP-induced nocifensive behavior in WT and TRPA1 K0 mice. $n=8-10 . \boldsymbol{F}$, Role of the TRPA1 channel in peripheral mechanisms of AM1241 (AM)-induced antinociception. Evaluation of the effect of preinjection of vehicle or AM1241 (40 $\mu \mathrm{g})$ in the ipsilateral paw (Ipsi) to desensitize CAP-induced nocifensive behavior in WT as well as TRPA1KO mice. $n=7-8$.

based knockdown approach, we demonstrated the involvement of TRPA1 in mediating WIN and AM1241 responses in sensory neurons. The treatment of TG neurons with TRPA1-specific siRNA blocked the WIN-evoked rise in $\left[\mathrm{Ca}^{2+}\right]_{\mathrm{i}}$ and inward currents as effectively as it inhibited MO responses in TG neurons, which are exclusively transmitted by the TRPA1 channel (Bautista et al., 2006). In contrast, silencing TRPA1 function only reduced AM1241 responses in a subset of sensory neurons. Another interesting property of AM1241 is that, unlike WIN, it activates much more effectively cells containing a mix of TRPA1 and TRPV1 rather than TRPA1 alone. In summary, these results are consistent with the hypothesis that WIN activates sensory neurons via the TRPA1 channel, whereas AM1241 responses in TG neurons are mediated by both TRPA1 and other unknown channels/receptors.

The TRPA1 channel belongs to the family of receptor-operated channels (Clapham, 2003), because it can be activated by intracellular $\mathrm{Ca}^{2+}$ store depletion (Jordt et al., 2004) and/or gated directly by diacylglycerol (DAG) (Bandell et al., 2004). A recent report indicated that secondmessenger signaling pathways could form a tenable link between WIN activity and increases in intracellular $\mathrm{Ca}^{2+}$ in hippocampus (Lauckner et al., 2005). Therefore, WIN and possibly AM1241 could activate TRPA1 indirectly via an induction of $\mathrm{G}_{\mathrm{q} / 11}$-coupled receptor(s) that in turn launch cellular cascades culminating in DAG production and/or internal $\mathrm{Ca}^{2+}$ store depletion leading to TRPAl activation. However, WIN was not able to induce phospholipase C (PLC) activities in TG neurons, whereas $50 \%$ of the same neurons displayed PLC activation by the inflammatory mediator bradykinin that activates $\mathrm{G}_{\mathrm{q} /}$ 11-coupled cellular pathways (Jeske et al., 2006). Thus, these data do not support the hypothesis of an indirect activation of the TRPA1 channel by cannabinoids in sensory neurons.

In the present study, we also provided evidence that the TRPA1 channel plays a critical role in WIN- and AM1241-evoked attenuation of $I_{\mathrm{CAP}}$ and $I_{\mathrm{MO}}$ in TG neurons. Recent investigations showed that inhibition of $I_{\text {CAP }}$ by WIN was dependent on extracellular $\mathrm{Ca}^{2+}$ and $\mathrm{a} \mathrm{Ca}^{2+}$ / calcineurin-dependent signaling pathway (Patwardhan et al., 2006a), and that WIN treatment of sensory neurons triggered TRPV1 dephosphorylation (Jeske et al., 2006). Together with the presented data, we propose that WIN and AM1241 may engage a similar mechanism for inhibition of responses to certain noxious chemical stimuli (Koplas et al., 1997; Liu and Simon, 1998). Indeed, the desensitization of CAP responses is very sensitive to extracellular $\mathrm{Ca}^{2+}$ influx (Koplas et al., 1997; Numazaki et al., 2003). This could be a reason why a trend toward $I_{\text {CAP }}$ inhibition was observed at concentrations of WIN and AM1241 $(2-10 \mu \mathrm{M})$ that are just sufficient to generate $\mathrm{Ca}^{2+}$ influx into TG 
neurons. One of the models proposed for the $\mathrm{Ca}^{2+}$-dependent mediation of $I_{\mathrm{CAP}}$ tachyphylaxis posits the location of a TRPV1desensitizing machinery in the vicinity of the channel pore (Numazaki et al., 2003; Jung et al., 2004). This model leads to the hypothesis that TRPA1 and TRPV1 may be located within distinct lipid microdomains or may heteromerize to share the same pore. Nevertheless, there is no evidence that this putative interaction is a critical step in achieving effective cannabinoid inhibition of CAP and especially MO responses. Indeed, the mechanisms of the WIN- and AM1241-induced inhibition of MO responses in sensory neurons are not clear. Moreover, $I_{\mathrm{MO}}$ tachyphylaxis in sensory neurons could involve both $\mathrm{Ca}^{2+}$-dependent and $\mathrm{Ca}^{2+}$-independent pathways (Akopian et al., 2007; Ruparel et al., 2008).

\section{Role of the TRPA1 channel in peripheral cannabinoid antihyperalgesia}

There is an agreement that cannabinoids could produce peripherally mediated antihyperalgesic and antinociceptive effects via a variety of mechanisms (Richardson et al., 1998; Rice et al., 2002; Malan et al., 2003; Walker and Hohmann, 2005). Thus, despite the similar potent $\mathrm{CB}_{2}$ agonist properties of both WIN and AM1241, differences in their peripheral inhibitory actions have been reported (Johanek et al., 2001; Quartilho et al., 2003; Hohmann et al., 2004; Ibrahim et al., 2006). A diversity of hypothesized mechanisms has been proposed because cannabinoids could mediate their actions via different receptors (or channels) that are differentially activated in various pain models or by distinct experimental approaches (e.g., local vs systemic injection). In addition, cannabinoids can modulate sensory neurons as well as non-neuronal peripheral cells that play an important role in nociceptive signal transmission (Calignano et al., 2001; Maccarrone et al., 2003; Samson et al., 2003; Ibrahim et al., 2005).

Peripheral cannabinoid antihyperalgesic and antinociceptive effects could be observed by activation of several targets, including $\mathrm{CB}_{1}$ or $\mathrm{CB}_{2}$ receptors and TRPV1 or TRPA1 channels. Certain cannabinoids evoke their peripheral effects by inhibiting or activating non-neuronal cells surrounding peripheral sensory neuron terminals. Thus, activation of $\mathrm{CB}_{2}$ leads to inhibition of mast cells and reduction of neutrophil accumulation (Jaggar et al., 1998; Calignano et al., 2001). This in turn could lead to antihyperalgesia (Woolf et al., 1996; Perkins and Tracey, 2000). Stimulation of $\mathrm{CB}_{2}$ receptor by cannabinoids such as WIN and AM1241 can also result in activation of keratinocytes and release of opioids, which are capable of inhibiting sensory neurons (Ibrahim et al., 2005). Indeed, in $\mathrm{CB}_{2}$ null-mutant mice, AM1241- and WINevoked peripheral thermal antinociception is completely and partially reversed, respectively (Ibrahim et al., 2006). Our data presented in supplemental Figure 2, $A$ and $B$ (available at www. jneurosci.org as supplemental material), are in agreement with this finding. CAP-induced nociception was fully reversed in $\mathrm{CB}_{2}$ null-mutant mice by AM1241 (supplemental Fig. $2 \mathrm{~A}$, available at www.jneurosci.org as supplemental material), but not WIN (supplemental Fig. $2 \mathrm{~B}$, available at www.jneurosci.org as supplemental material). Together, there could be agreement that certain cannabinoids (such as AM1241) can produce peripheral antinociception and probably antihyperalgesia by activating $\mathrm{CB}_{2}$ receptor located on non-neuronal cells surrounding sensory neuron peripheral terminals.

The $\mathrm{CB}_{1}$ receptor is another possible target for peripheral effects of certain cannabinoids. However, unlike the $\mathrm{CB}_{2}$ receptor, there are contradicting data on possible $\mathrm{CB}_{1}$ mechanisms. Analysis of $\mathrm{CB}_{1}$ null-mutant mice indicates that WIN-evoked periph- eral thermal antinociception could not be mediated by the $\mathrm{CB}_{1}$ receptor (Ibrahim et al., 2006). However, sensory neuronspecific ablation of $\mathrm{CB}_{1}$ receptor led to an $80 \%$ reversal of cannabinoid antihyperalgesia (including central effects) (Agarwal et al., 2007). Our data generated from analysis of $\mathrm{CB}_{1}$ null-mutant mice illustrate that WIN-stimulated $\mathrm{CB}_{1}$ receptor plays a role in the peripheral inhibition of CAP-induced nociception (supplemental Fig. 2C, available at www.jneurosci.org as supplemental material). However, we did not observe peripheral $\mathrm{CB}_{1}$-mediated effects as large as has been reported previously (Agarwal et al., 2007). In addition, there are still contradicting data on the site of cannabinoids actions that occur via activation of the $\mathrm{CB}_{1}$ receptor. Thus, a number of studies have demonstrated that $\mathrm{CB}_{1}$ has little-to-no coexpression with nociceptive markers such as the TRPV1 and CGRP in native rat DRGs (Hohmann and Herkenham, 1999; Bridges et al., 2003) and TGs (Price et al., 2003). In addition, the application of $\mathrm{CP} 55,940$, a dual $\mathrm{CB}_{1} / \mathrm{CB}_{2}$ agonist, inhibits the depolarization-evoked rise in intracellular $\mathrm{Ca}^{2+}$ $\left(\left[\mathrm{Ca}^{2+}\right]_{\mathrm{i}}\right)$ primarily in non-nociceptive (i.e., large-diameter) neurons (Khasabova et al., 2002, 2004). Depolarization-evoked CGRP release from TG neurons has also not been attenuated by concentrations of WIN capable of activating $\mathrm{CB}_{1} / \mathrm{CB}_{2}$ (Price et al., 2004b). In addition, the WIN-evoked inhibition of CAP responses in sensory neurons could not be reversed by inhibition of G-protein pathways (Patwardhan et al., 2006a). It was reported that the $\mathrm{CB}_{1}$ receptor can have tonic inhibitory effects on CAP responses in sensory neurons (Agarwal et al., 2007). However, data from our observations and other groups indicate that this tonic inhibition is neither observed in conventional $\mathrm{CB}_{1}$-null mutant mice (supplemental Fig. 2C, available at www. jneurosci.org as supplemental material) (Ibrahim et al., 2006) nor relieved by $\mathrm{CB}_{1}$ antagonists (Johanek et al., 2001; Malan et al., 2001; Johanek and Simone, 2004).

In addition to the metabotropic $\mathrm{CB}_{1}$ and $\mathrm{CB}_{2}$ receptors, certain cannabinoids can also activate channels, namely TRPV1 and TRPA1 (Zygmunt et al., 1999; Huang et al., 2002; Jordt et al., 2004; Price et al., 2004a). The present study is built on a number of previous observations: First, activities of TRPV1 and TRPA1 channels can undergo pharmacological desensitization (Docherty et al., 1996; Koplas et al., 1997; Story et al., 2003; Akopian et al., 2007; Ruparel et al., 2008). Therefore, the activation of TRPV1 or TRPA1 by cannabinoids could lead to inhibition of TRPV1 or TRPA1, respectively. Thus, the role of TRPV1 in cannabinoid-induced peripheral effects has been demonstrated (Price et al., 2004a; Sagar et al., 2004). Second, crossdesensitization between the TRPA1 and TRPV1 channels has been extensively characterized, and mechanisms underlying an interaction between these channels have been proposed (Brand and Jacquot, 2002; Jacquot et al., 2005; Akopian et al., 2007; Ruparel et al., 2008). Third, TRPA1 and TRPV1 are extensively colocalized in sensory neurons (Story et al., 2003; Obata et al., 2005; Diogenes et al., 2007). Finally, cannabinoid inhibition of CAP responses in sensory neurons is $\mathrm{Ca}^{2+} /$ calcineurin dependent and G-protein independent (Patwardhan et al., 2006a). Together, these observations have led to the hypothesis that certain cannabinoids can fulfill peripheral inhibitory effects by activating TRPA1 (or TRPV1) channel in sensory neurons. Herein, we provide strong evidence that the TRPAl channel is involved in the antinociceptive effects of WIN and AM1241. Peripherally restricted dosages of AM1241 and WIN inhibited CAP-induced nociception in WT mice, but not in TRPA1 KO littermates. Our data also demonstrate that the TRPA1 pathway is as effective as the $\mathrm{CB}_{1}$ and $\mathrm{CB}_{2}$ pathways in mediating peripheral cannabinoid 
effects in certain pain models (Fig. 8; supplemental Fig. 2, available at www.jneurosci.org as supplemental material). The relative contributions of these pathways in a broad range of pain models have not been studied as yet. However, differences in inhibitory efficacy could be expected for different cannabinoids. Thus, TRPA1 may not mediate $(6 \mathrm{a} R, 10 \mathrm{a} R)$ - trans-3 - (1,1'-dimethylheptyl)-6a,7,10,10a-tetrahydro-1hydroxy-6,6-dimethyl-6H-dibenzo[b,d]pyran-9-methanol (HU210)and CP55,940-induced peripheral antihyperalgesia (Ralevic and Kendall, 2001; Ellington et al., 2002), because the channel is not gated by HU210 or CP55,940 (Jordt et al., 2004). WIN- and AM1241-induced peripheral antihyperalgesia were also documented in certain pain models in which the functions of TRPA1 and TRPV1 are not clear (Caterina et al., 2000; Malan et al., 2001; Ibrahim et al., 2003; Bolcskei et al., 2005; Katsura et al., 2006). Finally, the roles of these channels in thermal, cold, and mechanical nociception in acute pain models have been debated (Woodbury et al., 2004; Bautista et al., 2006). Together, it could be proposed that cannabinoids produce peripheral inhibition by activating $\mathrm{CB}_{1}$ and/or $\mathrm{CB}_{2}$ located on peripheral non-neuronal cells and/or by activating the TRPA1 and TRPV1 channels located on sensory neurons. Cooperation between $\mathrm{CB}_{1}$ or $\mathrm{CB}_{2}$ and TRPAl pathways in peripheral cannabinoid antihyperalgesia and antinociception may also occur in some pain models.

In summary, the presented data support the hypothesis that TRPA1 is involved in peripherally mediated cannabinoid inhibition of CAP activities in sensory neurons. One important conclusion from this study is that, although cannabinoids differ in their activations of various receptors, they could exert inhibitory effects by acting through common ion channels. Therefore, it is conceivable that partial, TRPA1-specific agonists could constitute a novel class of peripherally selective analgesics without a variety of side effects of conventional cannabinoids.

\section{References}

Agarwal N, Pacher P, Tegeder I, Amaya F, Constantin CE, Brenner GJ, Rubino T, Michalski CW, Marsicano G, Monory K, Mackie K, Marian C, Batkai S, Parolaro D, Fischer MJ, Reeh P, Kunos G, Kress M, Lutz B, Woolf CJ, et al. (2007) Cannabinoids mediate analgesia largely via peripheral type 1 cannabinoid receptors in nociceptors. Nat Neurosci 10:870-879.

Ahluwalia J, Urban L, Capogna M, Bevan S, Nagy I (2000) Cannabinoid 1 receptors are expressed in nociceptive primary sensory neurons. Neuroscience 100:685-688.

Akopian AN, Ruparel NB, Jeske NA, Hargreaves KM (2007) Transient receptor potential TRPA1 channel desensitization in sensory neurons is agonist dependent and regulated by TRPV1-directed internalization. J Physiol (Lond) 583:175-193.

Amaya F, Shimosato G, Kawasaki Y, Hashimoto S, Tanaka Y, Ji RR, Tanaka M (2006) Induction of CB1 cannabinoid receptor by inflammation in primary afferent neurons facilitates antihyperalgesic effect of peripheral CB1 agonist. Pain 124:175-183.

Bandell M, Story GM, Hwang SW, Viswanath V, Eid SR, Petrus MJ, Earley TJ, Patapoutian A (2004) Noxious cold ion channel TRPA1 is activated by pungent compounds and bradykinin. Neuron 41:849-857.

Bautista DM, Jordt SE, Nikai T, Tsuruda PR, Read AJ, Poblete J, Yamoah EN, Basbaum AI, Julius D (2006) TRPA1 mediates the inflammatory actions of environmental irritants and proalgesic agents. Cell 124:1269-1282.

Binzen U, Greffrath W, Hennessy S, Bausen M, Saaler-Reinhardt S, Treede $\mathrm{RD}$ (2006) Co-expression of the voltage-gated potassium channel Kv1.4 with transient receptor potential channels (TRPV1 and TRPV2) and the cannabinoid receptor $\mathrm{CB} 1$ in rat dorsal root ganglion neurons. Neuroscience 142:527-539.

Bolcskei K, Helyes Z, Szabo A, Sandor K, Elekes K, Nemeth J, Almasi R, Pinter E, Petho G, Szolcsanyi J (2005) Investigation of the role of TRPV1 receptors in acute and chronic nociceptive processes using gene-deficient mice. Pain 117:368-376.

Brand G, Jacquot L (2002) Sensitization and desensitization to allyl isothiocyanate (mustard oil) in the nasal cavity. Chem Senses 27:593-598.

Bridges D, Rice AS, Egertova M, Elphick MR, Winter J, Michael GJ (2003)
Localisation of cannabinoid receptor 1 in rat dorsal root ganglion using in situ hybridisation and immunohistochemistry. Neuroscience 119:803-812.

Calignano A, La Rana G, Giuffrida A, Piomelli D (1998) Control of pain initiation by endogenous cannabinoids. Nature 394:277-281.

Calignano A, La Rana G, Piomelli D (2001) Antinociceptive activity of the endogenous fatty acid amide, palmitylethanolamide. Eur J Pharmacol 419:191-198.

Caterina MJ, Schumacher MA, Tominaga M, Rosen TA, Levine JD, Julius D (1997) The capsaicin receptor: a heat-activated ion channel in the pain pathway. Nature 389:816-824.

Caterina MJ, Leffler A, Malmberg AB, Martin WJ, Trafton J, Petersen-Zeitz KR, Koltzenburg M, Basbaum AI, Julius D (2000) Impaired nociception and pain sensation in mice lacking the capsaicin receptor. Science 288:306-313.

Clapham DE (2003) TRP channels as cellular sensors. Nature 426:517-524. Corey DP, Garcia-Anoveros J, Holt JR, Kwan KY, Lin SY, Vollrath MA, Amalfitano A, Cheung EL, Derfler BH, Duggan A, Geleoc GS, Gray PA, Hoffman MP, Rehm HL, Tamasauskas D, Zhang DS (2004) TRPA1 is a candidate for the mechanosensitive transduction channel of vertebrate hair cells. Nature 432:723-730.

Croxford JL (2003) Therapeutic potential of cannabinoids in CNS disease. CNS Drugs 17:179-202.

Diogenes A, Akopian AN, Hargreaves KM (2007) NGF up-regulates TRPA1: implications for orofacial pain. J Dent Res 86:550-555.

Distler C, Rathee PK, Lips KS, Obreja O, Neuhuber W, Kress M (2003) Fast $\mathrm{Ca}^{2+}$-induced potentiation of heat-activated ionic currents requires cAMP/PKA signaling and functional AKAP anchoring. J Neurophysiol 89:2499-2505.

Docherty RJ, Yeats JC, Bevan S, Boddeke HW (1996) Inhibition of calcineurin inhibits the desensitization of capsaicin-evoked currents in cultured dorsal root ganglion neurones from adult rats. Pflügers Arch 431:828-837.

Dogrul A, Gul H, Akar A, Yildiz O, Bilgin F, Guzeldemir E (2003) Topical cannabinoid antinociception: synergy with spinal sites. Pain 105:11-16.

Duncan M, Kendall DA, Ralevic V (2004) Characterization of cannabinoid modulation of sensory neurotransmission in the rat isolated mesenteric arterial bed. J Pharmacol Exp Ther 311:411-419.

Ellington HC, Cotter MA, Cameron NE, Ross RA (2002) The effect of cannabinoids on capsaicin-evoked calcitonin gene-related peptide (CGRP) release from the isolated paw skin of diabetic and non-diabetic rats. Neuropharmacology 42:966-975.

Fox A, Kesingland A, Gentry C, McNair K, Patel S, Urban L, James I (2001) The role of central and peripheral cannabinoid 1 receptors in the antihyperalgesic activity of cannabinoids in a model of neuropathic pain. Pain 92:91-100.

Gamper N, Shapiro MS (2003) Calmodulin mediates $\mathrm{Ca}^{2+}$-dependent modulation of M-type $\mathrm{K}^{+}$channels. J Gen Physiol 122:17-31.

Hannon GJ, Rossi JJ (2004) Unlocking the potential of the human genome with RNA interference. Nature 431:371-378.

Hohmann AG, Herkenham M (1999) Cannabinoid receptors undergo axonal flow in sensory nerves. Neuroscience 92:1171-1175.

Hohmann AG, Farthing JN, Zvonok AM, Makriyannis A (2004) Selective activation of cannabinoid $\mathrm{CB} 2$ receptors suppresses hyperalgesia evoked by intradermal capsaicin. J Pharmacol Exp Ther 308:446-453.

Hu HZ, Gu Q, Wang C, Colton CK, Tang J, Kinoshita-Kawada M, Lee LY, Wood JD, Zhu MX (2004) 2-Aminoethoxydiphenyl borate is a common activator of TRPV1, TRPV2, and TRPV3. J Biol Chem 279:35741-35748.

Huang SM, Bisogno T, Trevisani M, Al-Hayani A, De Petrocellis L, Fezza F, Tognetto M, Petros TJ, Krey JF, Chu CJ, Miller JD, Davies SN, Geppetti P, Walker JM, Di Marzo V (2002) An endogenous capsaicin-like substance with high potency at recombinant and native vanilloid VR1 receptors. Proc Natl Acad Sci USA 99:8400-8405.

Ibrahim MM, Deng H, Zvonok A, Cockayne DA, Kwan J, Mata HP, Vanderah TW, Lai J, Porreca F, Makriyannis A, Malan Jr TP (2003) Activation of CB2 cannabinoid receptors by AM1241 inhibits experimental neuropathic pain: pain inhibition by receptors not present in the CNS. Proc Natl Acad Sci USA 100:10529-10533.

Ibrahim MM, Porreca F, Lai J, Albrecht PJ, Rice FL, Khodorova A, Davar G, Makriyannis A, Vanderah TW, Mata HP, Malan Jr TP (2005) CB2 cannabinoid receptor activation produces antinociception by stimulating pe- 
ripheral release of endogenous opioids. Proc Natl Acad Sci USA 102:3093-3098.

Ibrahim MM, Rude ML, Stagg NJ, Mata HP, Lai J, Vanderah TW, Porreca F, Buckley NE, Makriyannis A, Malan Jr TP (2006) CB(2) cannabinoid receptor mediation of antinociception. Pain 122:36-42.

Jacquot L, Monnin J, Lucarz A, Brand G (2005) Trigeminal sensitization and desensitization in the nasal cavity: a study of cross interactions. Rhinology 43:93-98.

Jaggar SI, Hasnie FS, Sellaturay S, Rice AS (1998) The anti-hyperalgesic actions of the cannabinoid anandamide and the putative CB2 receptor agonist palmitoylethanolamide in visceral and somatic inflammatory pain. Pain 76:189-199.

Jeske NA, Patwardhan AM, Gamper N, Price TJ, Akopian AN, Hargreaves KM (2006) Cannabinoid WIN 55,212-2 regulates TRPV1 phosphorylation in sensory neurons. J Biol Chem 281:32879-32890.

Johanek LM, Simone DA (2004) Activation of peripheral cannabinoid receptors attenuates cutaneous hyperalgesia produced by a heat injury. Pain 109:432-442.

Johanek LM, Heitmiller DR, Turner M, Nader N, Hodges J, Simone DA (2001) Cannabinoids attenuate capsaicin-evoked hyperalgesia through spinal and peripheral mechanisms. Pain 93:303-315.

Jordt SE, Bautista DM, Chuang HH, McKemy DD, Zygmunt PM, Hogestatt ED, Meng ID, Julius D (2004) Mustard oils and cannabinoids excite sensory nerve fibres through the TRP channel ANKTM1. Nature 427:260-265.

Juliano RL, Dixit VR, Kang H, Kim TY, Miyamoto Y, Xu D (2005) Epigenetic manipulation of gene expression: a toolkit for cell biologists. J Cell Biol 169:847-857.

Jung J, Shin JS, Lee SY, Hwang SW, Koo J, Cho H, Oh U (2004) Phosphorylation of vanilloid receptor 1 by $\mathrm{Ca}^{2+} / \mathrm{calmodulin}$-dependent kinase II regulates its vanilloid binding. J Biol Chem 279:7048-7054.

Katsura H, Obata K, Mizushima T, Yamanaka H, Kobayashi K, Dai Y, Fukuoka T, Tokunaga A, Sakagami M, Noguchi K (2006) Antisense knock down of TRPA1, but not TRPM8, alleviates cold hyperalgesia after spinal nerve ligation in rats. Exp Neurol 200:112-123.

Khasabova IA, Simone DA, Seybold VS (2002) Cannabinoids attenuate depolarization-dependent $\mathrm{Ca}^{2+}$ influx in intermediate-size primary afferent neurons of adult rats. Neuroscience 115:613-625.

Khasabova IA, Harding-Rose C, Simone DA, Seybold VS (2004) Differential effects of $\mathrm{CB}_{1}$ and opioid agonists on two populations of adult rat dorsal root ganglion neurons. J Neurosci 24:1744-1753.

Kobayashi K, Fukuoka T, Obata K, Yamanaka H, Dai Y, Tokunaga A, Noguchi K (2005) Distinct expression of TRPM8, TRPA1, and TRPV1 mRNAs in rat primary afferent neurons with adelta/c-fibers and colocalization with trk receptors. J Comp Neurol 493:596-606.

Koplas PA, Rosenberg RL, Oxford GS (1997) The role of calcium in the desensitization of capsaicin responses in rat dorsal root ganglion neurons. J Neurosci 17:3525-3537.

Kwan KY, Allchorne AJ, Vollrath MA, Christensen AP, Zhang DS, Woolf CJ, Corey DP (2006) TRPAl contributes to cold, mechanical, and chemical nociception but is not essential for hair-cell transduction. Neuron 50:277-289.

Lauckner JE, Hille B, Mackie K (2005) The cannabinoid agonist WIN55,212-2 increases intracellular calcium via CB1 receptor coupling to Gq/11 G proteins. Proc Natl Acad Sci USA 102:19144-19149.

Liu L, Simon SA (1998) The influence of removing extracellular $\mathrm{Ca}^{2+}$ in the desensitization responses to capsaicin, zingerone and olvanil in rat trigeminal ganglion neurons. Brain Res 809:246-252.

Liu L, Lo Y, Chen I, Simon SA (1997) The responses of rat trigeminal ganglion neurons to capsaicin and two nonpungent vanilloid receptor agonists, olvanil and glyceryl nonamide. J Neurosci 17:4101-4111.

Maccarrone M, Di Rienzo M, Battista N, Gasperi V, Guerrieri P, Rossi A, Finazzi-Agro A (2003) The endocannabinoid system in human keratinocytes. Evidence that anandamide inhibits epidermal differentiation through CB1 receptor-dependent inhibition of protein kinase C, activation protein-1, and transglutaminase. J Biol Chem 278:33896-33903.

Malan Jr TP, Ibrahim MM, Deng H, Liu Q, Mata HP, Vanderah T, Porreca F, Makriyannis A (2001) CB2 cannabinoid receptor-mediated peripheral antinociception. Pain 93:239-245.

Malan Jr TP, Ibrahim MM, Lai J, Vanderah TW, Makriyannis A, Porreca F
(2003) CB2 cannabinoid receptor agonists: pain relief without psychoactive effects? Curr Opin Pharmacol 3:62-67.

Matsuda LA, Lolait SJ, Brownstein MJ, Young AC, Bonner TI (1990) Structure of a cannabinoid receptor and functional expression of the cloned cDNA. Nature 346:561-564.

McKemy DD, Neuhausser WM, Julius D (2002) Identification of a cold receptor reveals a general role for TRP channels in thermosensation. Nature 416:52-58.

McMahon SB, Wood JN (2006) Increasingly irritable and close to tears: TRPA1 in inflammatory pain. Cell 124:1123-1125.

Munro S, Thomas KL, Abu-Shaar M (1993) Molecular characterization of a peripheral receptor for cannabinoids. Nature 365:61-65.

Nackley AG, Makriyannis A, Hohmann AG (2003) Selective activation of cannabinoid $\mathrm{CB}(2)$ receptors suppresses spinal fos protein expression and pain behavior in a rat model of inflammation. Neuroscience 119:747-757.

Numazaki M, Tominaga T, Takeuchi K, Murayama N, Toyooka H, Tominaga M (2003) Structural determinant of TRPV1 desensitization interacts with calmodulin. Proc Natl Acad Sci USA 100:8002-8006.

Obata K, Katsura H, Mizushima T, Yamanaka H, Kobayashi K, Dai Y, Fukuoka T, Tokunaga A, Tominaga M, Noguchi K (2005) TRPA1 induced in sensory neurons contributes to cold hyperalgesia after inflammation and nerve injury. J Clin Invest 115:2393-2401.

Patwardhan AM, Jeske NA, Price TJ, Gamper N, Akopian AN, Hargreaves KM (2006a) The cannabinoid WIN 55,212-2 inhibits transient receptor potential vanilloid 1 (TRPV1) and evokes peripheral antihyperalgesia via calcineurin. Proc Natl Acad Sci USA 103:11393-11398.

Patwardhan AM, Diogenes A, Berg KA, Fehrenbacher JC, Clarke WP, Akopian AN, Hargreaves KM (2006b) PAR-2 agonists activate trigeminal nociceptors and induce functional competence in the delta opioid receptor. Pain 125:114-124.

Perkins NM, Tracey DJ (2000) Hyperalgesia due to nerve injury: role of neutrophils. Neuroscience 101:745-757.

Piomelli D (2003) The molecular logic of endocannabinoid signalling. Nat Rev Neurosci 4:873-884.

Piper AS, Yeats JC, Bevan S, Docherty RJ (1999) A study of the voltage dependence of capsaicin-activated membrane currents in rat sensory neurones before and after acute desensitization. J Physiol (Lond) 518:721-733.

Price TJ, Helesic G, Parghi D, Hargreaves KM, Flores CM (2003) The neuronal distribution of cannabinoid receptor type 1 in the trigeminal ganglion of the rat. Neuroscience 120:155-162.

Price TJ, Patwardhan A, Akopian AN, Hargreaves KM, Flores CM (2004a) Modulation of trigeminal sensory neuron activity by the dual cannabinoid-vanilloid agonists anandamide, $\mathrm{N}$-arachidonoyldopamine and arachidonyl-2-chloroethylamide. $\mathrm{Br} \mathrm{J}$ Pharmacol 141:1118-1130.

Price TJ, Patwardhan A, Akopian AN, Hargreaves KM, Flores CM (2004b) Cannabinoid receptor-independent actions of the aminoalkylindole WIN 55,212-2 on trigeminal sensory neurons. Br J Pharmacol 142:257-266.

Quartilho A, Mata HP, Ibrahim MM, Vanderah TW, Porreca F, Makriyannis A, Malan TP, Jr (2003) Inhibition of inflammatory hyperalgesia by activation of peripheral CB2 cannabinoid receptors. Anesthesiology 99:955-960.

Ralevic V, Kendall DA (2001) Cannabinoid inhibition of capsaicin-sensitive sensory neurotransmission in the rat mesenteric arterial bed. Eur J Pharmacol 418:117-125.

Rice AS, Farquhar-Smith WP, Nagy I (2002) Endocannabinoids and pain: spinal and peripheral analgesia in inflammation and neuropathy. Prostaglandins Leukot Essent Fatty Acids 66:243-256.

Richardson JD, Kilo S, Hargreaves KM (1998) Cannabinoids reduce hyperalgesia and inflammation via interaction with peripheral CB1 receptors. Pain 75:111-119.

Rosenzweig M, Brennan KM, Tayler TD, Phelps PO, Patapoutian A, Garrity PA (2005) The Drosophila ortholog of vertebrate TRPA1 regulates thermotaxis. Genes Dev 19:419-424.

Ross RA, Coutts AA, McFarlane SM, Anavi-Goffer S, Irving AJ, Pertwee RG, MacEwan DJ, Scott RH (2001) Actions of cannabinoid receptor ligands on rat cultured sensory neurones: implications for antinociception. Neuropharmacology 40:221-232.

Ruparel NB, Patwardhan AM, Akopian AN, Hargreaves KM (2008) Ho- 
mologous and heterologous desensitization of capsaicin and mustard oil responses utilize different cellular pathways in nociceptors. Pain, in press.

Sagar DR, Smith PA, Millns PJ, Smart D, Kendall DA, Chapman V (2004) TRPV1 and $\mathrm{CB}(1)$ receptor-mediated effects of the endovanilloid/ endocannabinoid $\mathrm{N}$-arachidonoyl-dopamine on primary afferent fibre and spinal cord neuronal responses in the rat. Eur J Neurosci 20:175-184.

Samson MT, Small-Howard A, Shimoda LM, Koblan-Huberson M, Stokes AJ, Turner H (2003) Differential roles of CB1 and CB2 cannabinoid receptors in mast cells. J Immunol 170:4953-4962.

Story GM, Peier AM, Reeve AJ, Eid SR, Mosbacher J, Hricik TR, Earley TJ, Hergarden AC, Andersson DA, Hwang SW, McIntyre P, Jegla T, Bevan S, Patapoutian A (2003) ANKTM1, a TRP-like channel expressed in nociceptive neurons, is activated by cold temperatures. Cell 112:819-829.
Walker JM, Hohmann AG (2005) Cannabinoid mechanisms of pain suppression. Handb Exp Pharmacol 2005:509-554.

Watanabe H, Davis JB, Smart D, Jerman JC, Smith GD, Hayes P, Vriens J, Cairns W, Wissenbach U, Prenen J, Flockerzi V, Droogmans G, Benham CD, Nilius B (2002) Activation of TRPV4 channels (hVRL-2/mTRP12) by phorbol derivatives. J Biol Chem 277:13569-13577.

Woodbury CJ, Zwick M, Wang S, Lawson JJ, Caterina MJ, Koltzenburg M, Albers KM, Koerber HR, Davis BM (2004) Nociceptors lacking TRPV1 and TRPV2 have normal heat responses. J Neurosci 24:6410-6415.

Woolf CJ, Ma QP, Allchorne A, Poole S (1996) Peripheral cell types contributing to the hyperalgesic action of nerve growth factor in inflammation. J Neurosci 16:2716-2723.

Zygmunt PM, Petersson J, Andersson DA, Chuang H, Sorgard M, Di Marzo V, Julius D, Hogestatt ED (1999) Vanilloid receptors on sensory nerves mediate the vasodilator action of anandamide. Nature 400:452-457. 